\title{
Actions and Therapeutic Potential of Madecassoside and Other Major Constituents of Centella asiatica: A Review
}

\author{
Swee Ching Tan ${ }^{1}$, Subrat Kumar Bhattamisra ${ }^{2}$, Dinesh Kumar Chellappan ${ }^{2, * \mathbb{D}}$ and Mayuren Candasamy ${ }^{2, *}$ \\ 1 School of Postgraduate Studies, International Medical University, Bukit Jalil, Kuala Lumpur 57000, Malaysia; \\ TanSweeChing@student.imu.edu.my \\ 2 School of Pharmacy, International Medical University, Bukit Jalil, Kuala Lumpur 57000, Malaysia; \\ SubratKumar@imu.edu.my \\ * Correspondence: Dinesh_Kumar@imu.edu.my (D.K.C.); MayurenCandasamy@imu.edu.my (M.C.); \\ Tel.: +603-2731-7280 (D.K.C.); +603-2731-7589 (M.C.)
}

check for

updates

Citation: Tan, S.C.; Bhattamisra, S.K.; Chellappan, D.K.; Candasamy, M. Actions and Therapeutic Potential of Madecassoside and Other Major Constituents of Centella asiatica: A Review. Appl. Sci. 2021, 11, 8475. https://doi.org/10.3390/app11188475

Academic Editors: Hari

Prasad Devkota and

Alessandra Durazzo

Received: 20 July 2021

Accepted: 4 September 2021

Published: 13 September 2021

Publisher's Note: MDPI stays neutral with regard to jurisdictional claims in published maps and institutional affiliations.

Copyright: (c) 2021 by the authors. Licensee MDPI, Basel, Switzerland. This article is an open access article distributed under the terms and conditions of the Creative Commons Attribution (CC BY) license (https:// creativecommons.org/licenses/by/ $4.0 /)$.

\begin{abstract}
Centella asiatica is a popular herb well-known for its wide range of therapeutic effects and its use as a folk medicine for many years. Its therapeutic properties have been well correlated with the presence of asiaticoside, madecassoside, asiatic and madecassic acids, the pentacyclic triterpenes. The herb has been extensively known to treat skin conditions; nevertheless, several pre-clinical and clinical studies have scientifically demonstrated its effectiveness in other disorders. Among the active constituents that have been identified in Centella asiatica, madecassoside has been the subject of only a relatively small number of scientific reports. Therefore, this review, while including other major constituents of this plant, focuses on the therapeutic potential, pharmacokinetics and toxicity of madecassoside.
\end{abstract}

Keywords: madecassoside; Centella asiatica; asiaticoside; asiatic acid; madecassic acid

\section{Introduction}

Centella asiatica (L.) Urb., is an ethnomedical tropical plant that belongs to the Apiaceae family. Locally known as pegaga, or more commonly known as 'Indian pennywort', it is a lightly aromatic, slender and perennial creeper that blooms in shady, marshy and humid areas in tropical and subtropical Asian countries such as Malaysia, India and China [1,2]. The plants have a creeping stem, rooting at the nodes, producing tufts of leaves and white or pink flowers [3]. This plant is widely consumed as a health drink, while also used as a vegetable in a variety of cuisines and traditional food recipes in Asian countries [4]. C. asiatica (CA) has been used extensively in Ayurvedic and Chinese traditional medicine for hundreds of years to treat dermatological diseases, including bacterial infections, psoriasis, scleroderma, ulcer, leprosy and also skin inflammation due to wounds and burns [5-9]. Moreover, C. asiatica has also been reported to have neurological actions, including neuroprotective, memory-enhancing, antidepressant and anxiolytic effects $[4-6,8,10,11]$. Due to the outcome of in vitro and in vivo studies, as well as their cost effectiveness, easy access and low observed toxicity, C. asiatica extracts have been investigated clinically in various fields. A study found that CA lowered stress, attenuated anxiety, negated depression and enhanced adjustment and attention in patients with general anxiety disorder without any adverse effects [12]. CA was also reported to exert anxiolytic activity [13], as well as improve mood, behavior and cognitive functions [14-16]. Furthermore, CA has been used widely in treating vascular diseases, such as venous hypertensive microangiopathy [17-20], diabetic microangiopathy [21,22] and chronic venous insufficiency [23,24]. Clinical trials of CA have also been undertaken in other conditions, including leprosy [25], chronic hepatic disorder [26] and gastric ulcers [27-29]. With the abundant literature available on therapeutic effects of CA, it is worthwhile to explore into the compounds that is/are responsible for the effects. 
The novelty of this review is it highlights the compound madecassoside, as it's potential have not been tapped into vastly. This review also compiles the pharmacological activities of the main constituents, that has not been published previously.

\section{Methodology}

An extensive literature search was performed to identify the major constituents responsible for the reported pharmacological properties of $C$. asiatica. Furthermore, an attempt to summarize the common mechanism was made. Various electronic databases, such as Science Direct, PubMed, Taylor and Francis, Wiley, along with Google Scholar search engine were used for the literature survey. Papers with information on phytocompounds, medicinal properties, traditional practices and clinical trials were included. The literature cited in this review paper consists of 261 references which includes research and review papers. The search terms used in combination were Centella asiatica, madecassoside, asiaticoside, madecassic acid, asiatic acid, pharmacokinetics, toxicity profile and pharmacological properties. Studies or trials that did not include basic details were excluded. The results were compared, correlated and discussed to help researchers to further explore the possibilities of using the compounds in other research areas as well as clinical trials. The summary of the methodology adopted in the development of this review is illustrated in Figure 1.

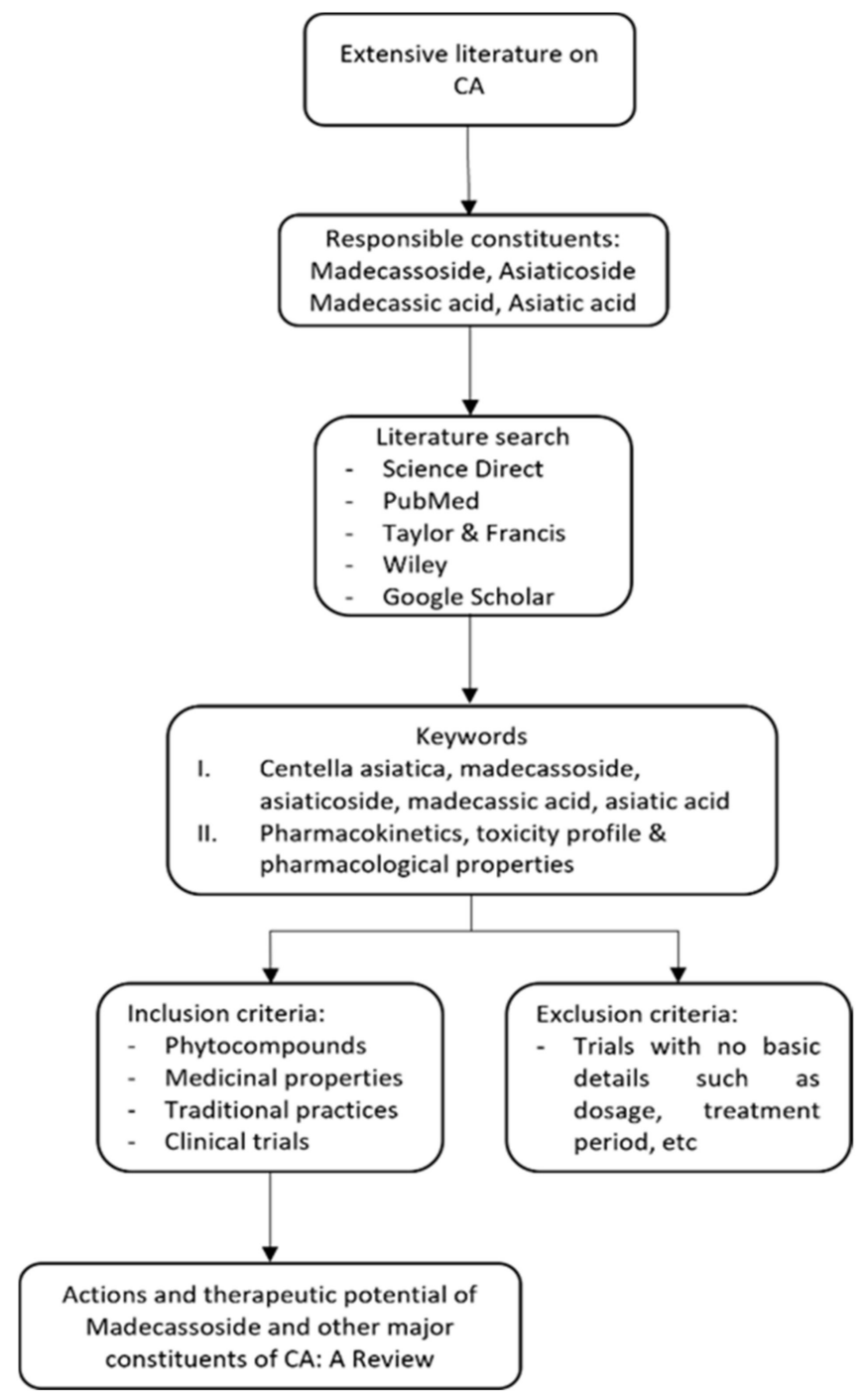

Figure 1. Summary of methodology. 


\section{Active Constituents of $C$. asiatica}

Inconsistent pharmacological activities of $C$. asiatica extracts harvested from various origins were reported; these extracts displayed substantial variations in the quality and quantity of their bioactive compounds [11]. Previous analytical studies showed C. asiatica to contain triterpenoids, amino acids and essential oils. The most important bioactive compounds are triterpene glycosides (saponins), such as asiaticoside and madecassoside, along with their respective aglycones (sapogenins), asiatic acid and madecassic acid $[5,8,10,30-32]$. These four major compounds, also known as pentacyclic triterpenes, are claimed to be responsible for the biological effects of $C$. asiatica extracts (Figure 2). Other constituents include oxyasiaticoside, centelloside, brahmoside, brahminoside, thankunoside, isothankunoside, brahmic acid, isobrahmic acid, betulic acid, $\beta$-sitosterol, hexacosanol octanoate, kaempferol, quercetin, daucosterol, vanillic acid and succinic acid $[2,7,9,33,34]$. Madecassoside and asiaticoside are identified as the biomarker components of this plant extract, due to their high contents relative to other constituents, with the content of madecassoside $\left(\mathrm{C}_{48} \mathrm{H}_{78} \mathrm{O}_{20}\right)$ being the highest [35].

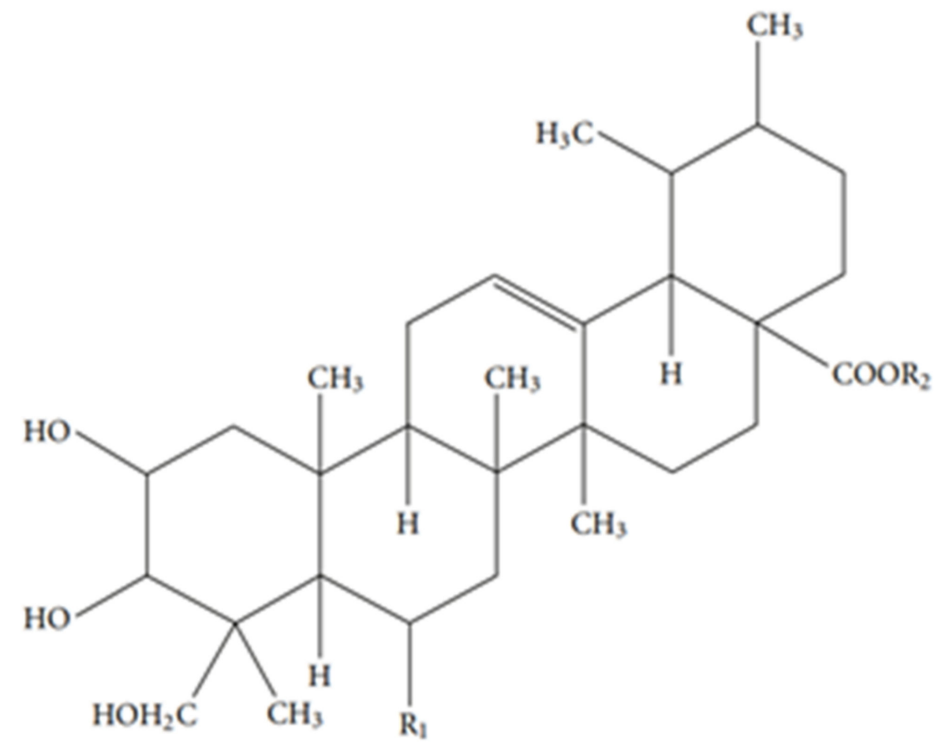

$$
\begin{array}{lll}
\text { Madecassoside } & \mathrm{R}_{1}=\mathrm{OH} & \mathrm{R}_{2}=\text { Glu-Glu-Rha } \\
\text { Asiaticoside } & \mathrm{R}_{1}=\mathrm{H} & \mathrm{R}_{2}=\text { Glu-Glu-Rha } \\
\text { Madecassic acid } & \mathrm{R}_{1}=\mathrm{OH} & \mathrm{R}_{2}=\mathrm{H} \\
\text { Asiatic acid } & \mathrm{R}_{1}=\mathrm{H} & \mathrm{R}_{2}=\mathrm{H}
\end{array}
$$

Figure 2. Chemical structures of madecassoside, asiaticoside, madecassic acid and asiatic acid (Glu: glucose, Rha: rhamnose).

Several methods have been used to quantify the triterpene content of Centella extracts. These include thin-layer chromatography and mass spectrometry (TLC-MS) [36], TLC coupled to high-speed counter-current chromatography [37,38], ultraviolet-visible spectroscopy (UVS) [39], high performance liquid chromatography (HPLC) [40-42], HPTLC [37,42-45], HPLC-electrospray ionization-mass spectrometry (HPLC-ESI-MS) [6], HPLC-ultraviolet (HPLC-UV) [5,41,46], and HPLC-paired with evaporative light scattering detector (HPLC-ELSD) [5,42]. Among these methods, some are comprised of multiple-step extraction and/or purification processes. These techniques have limited sensitivity and specificity, while necessitating long analysis cycles to acquire satisfactory chromatographic separation. High-performance anion-exchange chromatography combined with pulsed amperometric detection (HPAEC-PAD) is often used to quantify carbohydrates in plant extracts, allowing absolute detection of carbohydrates with great sensitivity [5]. Glycosides have previously been analyzed using reversed phase HPLC-PAD, where the compounds 
were detected following chromatographic separation. For example, madecassoside and asiaticoside were detected within 5 min of sample pre-treatment by combination with a post-column sodium hydroxide solution using the reversed phase HPLC-PAD method [5].

Although the quantification of $C$. asiatica triterpenes have been corroborated by numerous researchers using HPLC-UV and HPTLC, variations in the triterpene content of extracts were found, depending on the location and the diverse environmental conditions for the growth of the plant. An investigation of the chemotypic variations of active biomarkers in relation to morphotypic changes in C. asiatica found no distinct disparity in botanical descriptors, physicochemical parameters or in bioactive metabolites quantified through HPTLC; this led the team to conclude that morphotypic variations do not always lead to chemotypic variations in C. asiatica [33].

A different approach using a polyclonal antibody against madecassoside, ELISA and Eastern blotting was used to quantitatively analyze triterpene glycosides in C. asiatica. ELISA was used to determine total madecassoside and asiaticoside content, whereas Eastern blotting was used to separate and quantify madecassoside and asiaticoside. These methods are faster, more straightforward and cost effective compared to HPLC [4].

\section{Pharmacokinetics of $C$. asiatica Constituents}

Over the years, countless small molecules derived from natural products have failed to progress to clinical studies, due to poor pharmacokinetic properties. Pharmacokinetics and bioavailability are major barriers in drug development. Oral bioavailability is an important factor to achieve the efficacious therapeutic concentrations of the drug, as it also denotes the most ideal route of drug administration [47].

Several studies have examined the pharmacokinetics of asiatic acid in rats and dogs [48-50]. With oral dosing, asiatic acid achieves a maximum plasma concentration $\left(c_{\max }\right)$ after $30 \mathrm{~min}$, indicating rapid gastrointestinal absorption. However, it is absorbed poorly and follows passive diffusion, with a major site of absorption in the jejunum, followed by rapid metabolism in the liver by cytochrome P450 enzymes [50]. Bioavailability studies have shown that asiatic acid may cross the blood-brain barrier (BBB), as the concentration of asiatic acid attained in the brain appears to be adequate to elicit neuroprotection [51-54]. The pharmacokinetics of asiatic acid present in a total triterpenic fraction of C. asiatica were studied in a randomized crossover design, administrating a single oral dose or repeated oral doses to healthy volunteers. Difference in dosage or treatment schemes did not affect the time taken to achieve peak plasma concentration. However, a chronic treatment protocol demonstrated increased half-life $\left(t_{1 / 2}\right), \mathrm{AUC}_{0-24}$ (area under the plasma concentration-time curve from zero to $24 \mathrm{~h}$ ) and $\mathrm{c}_{\max }$ [55]. The pharmacological effects and therapeutic benefits of asiaticoside are mediated by its in vivo metabolic conversion to asiatic acid [56]. Following intravenous administration of asiaticoside to rats, it is widely distributed in several organs and metabolized extensively, then finally recovered as asiatic acid in feces [10]. Asiatic acid is a non-toxic compound with an $\mathrm{LD}_{50}$ value of $980 \mathrm{mg} / \mathrm{kg}$ in rats [57].

Pharmacokinetic studies of madecassoside in rats have shown a $c_{\max }$ of $303.75 \pm 28.53 \mathrm{ng} / \mathrm{mL}$ after a single-dose oral administration of $100 \mathrm{mg} / \mathrm{kg}$ [6]; it was hypothesized that madecassoside could be metabolized to madecassic acid by intestinal bacteria [6,35]. Another pharmacokinetic study conducted using collagen-induced arthritic (CIA) rats showed the $\mathrm{c}_{\max }$ and AUC of madecassoside to be notably reduced, while the $\mathrm{Vd} / \mathrm{f}$ was augmented during the initial seven days of dosing. On the other hand, the $\mathrm{T}_{1 / 2}, \mathrm{C}_{\mathrm{max}}$ and AUC of madecassic acid were prominently elevated, with a significant reduction of elimination rate constant $\left(\mathrm{K}_{\mathrm{e}}\right)$ in CIA rats compared with normal rats. This study showed that the pharmacokinetic parameters of both madecassoside and madecassic acid in rats were substantially altered by arthritis status [58]. Another study compared pharmacokinetic changes of madecassoside and asiaticoside following the administration as pure compounds and ECa 233, a standardized extract of $C$. asiatica with madecassoside $(51 \%)$ and asiaticoside $(38 \%)$ in male Wistar rats. The $\mathrm{AUC}_{0-\infty}$ of madecassoside from $\mathrm{ECa}$ 
233 was 2 -fold higher than that of pure madecassoside. Furthermore, the elimination halflife of madecassoside and asiaticoside as pure compounds were approximately $4 \mathrm{~h}$, while the elimination half-life of madecassoside and asiaticoside as ECa 233 were prolonged. The study suggested that the pharmacokinetic behavior of madecassoside and asiaticoside was improved when administered as ECa 233 compared to pure compounds [10].

\section{Toxicity Profile of $C$. asiatica Constituents}

There is a scarcity of literature relating to the adverse effects and toxicity of C. asiatica. In a recommended dosage in humans C. asiatica is not toxic and side effects are rare, although it may cause skin allergy and burning sensations with external use, and in high doses, headache, upset stomach, nausea, dizziness and drowsiness were observed [59]. Contact dermatitis cases were reported on a few occasions from using topical preparations that contained C. asiatica [60-65]. The median lethal dose of dried powder of C. asiatica given orally to mice was greater than $8 \mathrm{~g} / \mathrm{kg}$, attesting to the lack of acute toxicity of the dried plant [66]. In a chronic toxicity study, 20, 200,600 and $1200 \mathrm{mg} / \mathrm{kg} /$ day of C. asiatica were given to Wistar rats for six months. At the end of the study, treated animals showed no significant changes in body weight, blood chemistry, clinical chemistry and histopathology when compared to the control group [67]. However, in contrast, oral administration of dried C. asiatica at a dose of $1000 \mathrm{mg} / \mathrm{kg} /$ day for 30 days to albino rats produced hepatic damage [68]. Furthermore, there is also a report on the risk of hepatotoxicity in humans treated with $C$. asiatica for 20-60 days [69]. Although C. asiatica was rarely reported to cause any adverse effects, it is advised not to be consumed by women during pregnancy and lactation, as it may have emmenagogue effects [70]. Extended treatment with high doses appears to reduce the metabolism of active constituents, which may increase the risk of toxicity; this should be considered during pharmacotherapy [55].

There are few studies on the toxicity of individual constituents of C. asiatica. One study reported that asiaticoside did not exhibit any signs of toxicity after oral administration of $1 \mathrm{mg} / \mathrm{kg}$. However, intramuscular injection of asiaticoside caused toxicity in mice and rabbits at $40-50 \mathrm{mg} / \mathrm{kg}$ [71]. Asiaticoside was also implicated as a weak carcinogen after repeated topical application on hairless mice [72]. Drug-drug interactions are possible with asiaticoside and/or madecassoside, as they were shown to inhibit human cytochrome P450 enzymes that are responsible for drug metabolism [73].

\section{Therapeutic Actions of Madecassoside and Other Major Compounds in C. asiatica}

Despite the extensive use of Centella asiatica as a traditional remedy, there have been few clinical studies because the drug delivery of a whole plant extract is more challenging compared to individual compounds. Therefore, attention has been focused on the isolation, production and medicinal efficacy of its bioactive compounds. This review focuses on madecassoside, asiaticoside, asiatic acid and madecassic acid, which have been researched considerably in recent years. A summary of the recent findings (from year 2015 to 2021) for the various conditions discussed below is presented in Table 1.

\subsection{Skin Related Disease or Wound}

C. asiatica has been used extensively in traditional medicines for treating skin related wounds and diseases, such as ulcerous skin abnormalities, lupus, scleroderma, leprosy [74]; a small number of studies have suggested that the beneficial effects are due to madecassoside, the most abundant triterpene present in extracts of C. asiatica [75]. Many studies suggested that madecassoside is beneficial in a variety of skin disorders, in which it may prevent skin aging and promote wound healing, as well as exerting anti-inflammatory and anti-psoriasis effects [76]. These effects of madecassoside may be due to its ability to protect against lipid peroxidation, and intensify collagen synthesis and expression while stimulating angiogenesis [77]. 
The most widely studied effects of C. asiatica extract and madecassoside have been in the context of burn wound healing. Burn wounds are categorized as tissue injury caused by external triggers, such as heat, chemicals, radiation and electricity [74]. Burn wounds could be classified into three degrees, predominantly based on the complexity of the wound incurred; these are superficial (first degree), partial thickness (second degree) and full thickness (third degree). Burn wound healing is complex, comprising an array of processes. It commences with inflammation that interrupts blood vessels and stimulates blood constituents to be released to the target area to stimulate re-epithelialization; followed by the formation of granulation tissue consisting of macrophages and fibroblasts that are responsible for extracellular matrix recovery; neo-vascularization towards the target area; in addition to mitogenic stimulation and migration of cells of endothelial origin. Finally, communication between extracellular matrix cells and cytokines results in wound contraction [74]. In rats, madecassoside and asiaticoside were reported to possess wound healing properties [74]. Madecassoside was shown to augment inflammatory cell infiltration, and to nurture re-epithelialization to achieve an almost complete wound closure with an improved healing pattern in the burned skin on mice [78]. Furthermore, in vitro studies have demonstrated the ability of madecassoside to promote type I and III collagen synthesis and to stimulate the proliferation of cultured human fibroblasts [78]; similar findings were also reported for asiaticoside [79]. Madecassoside was shown to augment endothelial cell growth in rat aortic rings in vitro, and to markedly increase angiogenesis in mouse burn wounds; it was hypothesized that madecassoside expedites burn wound healing through increased antioxidative activity, enriched collagen synthesis and angiogenesis [78]. In a separate study, madecassoside was shown to protect human umbilical vein endothelial cells (HUVECs) against hydrogen peroxide-induced lipid peroxidation and apoptosis via protecting the mitochondrion membranes, and inhibiting the activation of caspase-3 and p38 MAPK [80]. Similar studies have also been conducted to test the efficacy of asiaticoside in wound healing. Asiaticoside treatment increased migration rates and initial attachment of skin cells, while promoting normal human dermal fibroblast proliferation [81]. Asiaticoside also exhibited significant wound healing activity in normal as well as delayed healing models [82]. A study suggested that the enhancement of burn wound healing by asiaticoside could be due to the promotion of angiogenesis as a result of stimulation of the production of vascular endothelial growth factor (VEGF), caused by an increased expression of monocyte chemoattractant protein-1 (MCP-1) in keratinocytes, even at very low doses of asiaticoside (10 pg, $1 \mathrm{ng}$ and $100 \mathrm{ng}$ per mouse) [83]. Furthermore, the augmented healing produced by asiaticoside could be due to its capacity to enhance tissue antioxidant levels [84]; this study also suggested that asiaticoside would be helpful in wound repair only if applied during the active/initial phase of healing [84]. Asiaticoside has also showed potential in accelerating wound healing in a fish model via increased cellular proliferation and suppressed apoptosis [85].

Skin aging is a multifaceted biological process molded by a combination of endogenous or intrinsic (genetics, cellular metabolism, hormone and metabolic processes) and exogenous or extrinsic (chronic light exposure, pollution, ionizing radiation, chemicals, toxins) factors. It is characterized by features, such as wrinkling, loss of elasticity, laxity and a rough textured appearance. Madecassoside showed protective effects against oxidative stress and UVB radiation. It significantly inhibited UV-induced melanin synthesis and melanosome transfer in a co-culture system of keratinocytes and melanocytes, by suppressing PAR-2 expression and its signaling pathway involving COX-2, PGE2 and PGF2 $\alpha$ in keratinocytes [86]. Several traditional Chinese medicine practitioners have shown a therapeutic effect of madecassoside in the re-pigmentation of vitiligo and post-inflammatory hyperpigmentation. For example, madecassoside showed an anti-oxidative effect in human melanocytes exposed to hydrogen peroxide; here, it attenuated mitochondrial damage and promoted autophagy [87]. Madecassoside was also reported to impede the proliferation of SVK-14 keratinocytes, a cell line useful for investigating psoriasis [88]. In an in vivo mouse model of psoriasis-like inflammation induced by the immune response modifier 
imiquimod (IMQ), topically applied madecassoside decreased dermal inflammation and reduced keratinocyte proliferation. These effects were associated with a reduction in the elevated expression of IL-22, IL-17 and IL-23, and a reduction in the number of Th17 cells in the spleen and cervical lymph nodes [89]. Such observations suggest that madecassoside could be a novel treatment for psoriasis. Skin aging is primarily associated with reduction in type I collagen levels. As mentioned above, asiaticoside was reported to induce type I collagen; thus, it was hypothesized that asiaticoside induces an anti-wrinkle effect by elevating type I collagen levels through T $\beta$ RI kinase-independent Smad signaling pathway [90]. Micropthalmia-associated transcription factor (MITF) regulates key enzymes in melanocytes, which is important for hyper- or hypopigmentation diseases. Asiaticoside was shown to be a novel candidate for melanogenesis inhibition through repression of DNA binding to MITF [91]. Advanced glycation end-products (AGEs) accumulate in skin and cause overproduction of free radicals and inflammatory cytokines that enhance skin aging. Pre-treatment with asiatic acid protected HaCaT cells against AGE-induced injury. Asiatic acid exhibited antioxidative, anti-inflammatory and antiapoptotic effects by reducing ROS production and decreasing caspase activity [92]. Moreover, asiatic acid also prevented UVA irradiation-induced ROS production, lipid peroxidation and induction of MMP-2, as well as preventing UVA-enhanced expression of p53 in HaCaT cells [93].

Keloids result from an anomalous wound healing process: they are regarded as benign dermal tumors, as they proliferate beyond the boundaries of the original wound without regressing spontaneously [94]. Keloids cause substantial cosmetic defects and deformities, and can sometimes limit joint mobility. Although there are no reports of keloids transforming into malignant tumors, the invasion activity of keloid fibroblasts (KF) is comparable to some extent to that of malignant cells [94]. Treatment of human keloid-derived fibroblasts with madecassoside $(10,30$ and $100 \mu \mathrm{M})$ for $48 \mathrm{~h}$ inhibited their proliferation and migration in a time- and concentration-dependent manner, while inducing KF to undergo apoptosis [94]. Additionally, madecassoside depolarized the mitochondrial membrane, activated caspase- 9 and caspase- 3 and regulated the expression of Bcl-2 family members in KFs, implying that madecassoside induced KF apoptosis through a mitochondrialdependent pathway. These effects were associated with a marked attenuation of phosphorylation of cofilin, and p38 MAPK of phosphatidylinositol-3-kinase (PI3K)/AKT signaling. This study provided an explanation for the mechanism whereby madecassoside attenuates the formation of keloid scars and suggests that madecassoside could be of immense benefit for treating and/or preventing hypertrophic scars or keloids [94]. While madecassoside was proposed to exert its effects through a mitochondrial-dependent pathway, asiaticoside was suggested to hinder the invasive growth of KFs by inhibiting the growth differentiation factor-9 (GDF-9)/MAPK/Smad pathway [95]. Another study suggested that asiaticoside inhibited keloid-derived fibroblast proliferation and collagen synthesis. This study demonstrated that asiaticoside could negatively regulate the expression of both TGF- $\beta$ RI and TGF- $\beta$ RII while increasing inhibition of Smad7 expression, thereby altering fibroblast proliferation and collagen production [96]. Similar findings were also reported in separate studies [97-99]. Likewise, asiatic acid also inhibited TGF- $\beta$ I-induced collagen type I and plasminogen activator inhibitor-1 (PAI-1) expression, while increasing Smad7 protein level in KFs via activation of PPAR- $\gamma$ [100].

\subsection{Rheumatoid Arthritis}

Rheumatoid arthritis (RA) is a systemic disease distinguished by chronic inflammation, synovial hyperplasia with concomitant joint destruction, deformity and loss of function [101]. Collagen II (CII) is the core constituent protein of the cartilage in the diarthrodial joint, which is the principal site affected in RA [102]. The presence of heterologous CII species in the articular cartilage of joints initiates an immune response and Type II collagen-induced arthritis (CIA) is a well-established in vivo model for assessing the effects of anti-inflammatory or anti-rheumatic drugs, as it expresses similar immunological and pathological traits to human RA [103]. Oral administration of madecassoside to 
mice with CIA produced a dose-dependent reduction in paw inflammatory swelling and erythema, but did not modify the disease-associated body weight loss. Moreover, it also radically ameliorated the pathological indicators, including infiltration of inflammatory cells into the joint cavity, synovial hyperplasia, pannus formation and erosion of bone and cartilage [104]. It was hypothesized that madecassoside downregulated the abnormal humoral and cellular immunity, such as the overproduction of auto-antibodies and the excessive activation of T lymphocytes as well as joint destruction [104]. Another study suggested that the anti-inflammatory effect of madecassoside in mice with CIA may be associated with the inhibition of the production of TNF- $\alpha, \mathrm{IL}^{-6}, \mathrm{PGE}_{2}$ and the expression of COX-2, as well as the upregulation of the expression of the anti-inflammatory cytokine IL-10 [105]. Systemic levels of IL-10 were shown to be increased in rats with CIA receiving madecassoside, although the secretion of IL-10 from peripheral mononuclear cells was not enhanced [106]. Furthermore, madecassoside treatment led to a prominent increase in Foxp $3^{+}$lymphocytes in the intestinal lamina propria, one of the major sources of IL-10. This study suggested that the anti-arthritic effects of madecassoside in rats were mediated primarily through intensifying the secretion of IL-10 from Foxp $3^{+}$lymphocytes in the intestinal lamina propria and the mobilization of IL-10 to the circulation, rather than by a systemic anti-inflammatory action [106].

Cytokines are acknowledged to stimulate fibroblast-like synoviocytes (FLS) to produce MMPs, which damage the collagen component of cartilage and bone, contributing to the joint deformity and pain in RA patients [107]. MMP-13 is one of the most important collagenases responsible for damaging the articular cartilage and is often found in higher levels in the synovial fluids of RA patients [108]. The chief inducer of MMP-13 is IL-1 $\beta$, mainly through pathways involving NF-kB [109]. Madecassoside reversed the histological lesions in adjuvant-induced arthritis rats and suppressed IL- $1 \beta$-induced invasion and migration of FLS, as well as inhibited the expression of MMP-13 in FLS but with little effect on the expression of other MMPs. Additionally, madecassoside attenuated IL- $1 \beta$-stimulated p65 phosphorylation and translocation. These data suggested that madecassoside inhibited MMP-13 by preventing NF- $\mathrm{kB}$ translocation and phosphorylation [110].

As described earlier, the pharmacokinetics of madecassoside may be influenced by the presence of arthritis. Thus, the metabolism of madecassoside and the absorption of its metabolite madecassic acid were amplified in rats with CIA. This may be related to arthritisinduced changes in the levels of inflammatory cytokines, the activity of intestinal bacteria and the expression of hepatic drug metabolizing enzymes [58]. No studies appear to have been reported on the anti-arthritic effects of asiaticoside, asiatic acid and madecassic acid.

\subsection{Neurodegenerative Diseases}

Neurodegeneration entails numerous cellular processes whereby neuronal cells gradually deteriorate, lose functionality and eventually die [111]. Neurons are susceptible to ROS-induced oxidative damage resulting from ROS-induced oxidation of various biological macromolecules, causing homeostatic disturbances within neurons leading to cell death. Neuroinflammation is one of the key risk factors of progressive neurodegeneration [112]. The accumulation of ROS and protein misfolding associated with neuroinflammation could be one of several triggers of neurodegeneration [111]. Some studies have implicated neuroinflammation in aggravating Alzheimer's disease (AD) and Parkinson disease (PD), by stimulating excessive production of amyloid $\beta$ plaques and the destruction of dopaminergic neurons [111]. Several studies have suggested the potential of $C$. asiatica extract to mitigate symptoms of various neurodegenerative diseases, such as memory impairment, anxiety and locomotive dysfunction [113]. It has been used extensively as a memory-enhancing drug in Asian countries, such as India, China and Malaysia, and has been shown to have some pharmacological activities in the central nervous system [114]. Additionally, C. asiatica extracts were also reported to possess anticonvulsant and central nervous system depressant actions [59]. 
Purified madecassoside was shown to inhibit in vitro $A \beta_{1-42}$ fibril formation and to markedly inhibit $A \beta_{1-42}$ induced apoptosis in SHSY5Y cells [115]. Long-term oral administration of madecassoside protected against spatial memory impairment in $A \beta_{1-42}$-infused rats, a model of $A D$, as well as inhibiting the formation of $A \beta_{1-42}$ fibrils [116]. Madecassoside also diminished the brain $\mathrm{A} \beta_{1-42}$ burden, oxidative stress, TNF $\alpha$ and cathepsin $\mathrm{D}$ levels, along with a parallel increase in BDNF and postsynaptic density protein (PSD-95) levels in the hippocampus. The interaction of madecassoside with $A \beta_{1-42}$ by molecular docking was examined to further assess the anti- $\mathrm{A} \beta_{1-42}$ fibrillation effect of madecassoside. Computational modeling studies showed effective molecular docking of madecassoside onto $A \beta_{1-42}$, consistent with the inhibitory effects of madecassoside on in vitro fibril formation and memory impairment in a rat model of AD [116]. In agreement with these findings, madecassoside was found to markedly improve D-galactose-induced cognitive impairment in mice; this may be mediated by reducing oxidative damage via the inhibition of the NF- $\mathrm{kB}$ and ERK/p38 MAPK pathways, and diminishing the deposition of $A \beta$, thus ameliorating the synaptic plasticity dysfunction with amplified BDNF and PSD-95 expressions in the hippocampus. Furthermore, madecassoside notably enhanced acetylcholine levels while diminishing cholinesterase activity [112]. In another study, madecassoside significantly reduced $A \beta_{25-35}$-induced autophagosomes in neural cells and increased neural cell viability, as well as reducing the production of inflammatory cytokines such as TNF- $\alpha$, IL-10, IL-6 and COX-2, blocking the conversion of light chain 3-I (LC3-I) to light chain 3-II (LC3-II) and decreasing the level of Beclin-I level. All of the above findings suggest that madecassoside could be a potential agent for treating AD [112]. Asiaticoside also has been researched considerably as a therapeutic agent for AD. In an AD rat model induced by intracerebroventricular injection of $A \beta_{1-42}$ oligomers, asiaticoside diminished learning and memory function impairment, reduced $A \beta$ build-up in the hippocampus and reinstated subcellular structure damages. Asiaticoside also decreased levels of IL- 6 and TNF- $\alpha$ as well as caspase3 expression, while amplifying Bcl-2 expression [117]. Moreover, asiaticoside attenuated $\mathrm{A} \beta_{1-42}$-induced cytotoxicity and apoptosis, restored declined mitochondrial membrane potential and significantly downregulated TNF- $\alpha$, IL-6, TLR4, MyD88 and TRAF6 expressions in human brain microvascular endothelial cells (hBMECs) [118]. Administration of asiaticoside to senescence-accelerated mice (SAMP) averted spatial learning and decline by scavenging free radicals, increasing antioxidant enzymes activities, reducing $A \beta$ load, ameliorating synaptic plasticity dysfunction and keeping ACh levels and AChE activity in check [119]. Furthermore, asiaticoside effectively protected HUVECs against impairment elicited by aggregated $A \beta_{1-42}$, by promoting cell proliferation, apoptosis inhibition and the elevation of the Bcl-2/Bax ratio [120]. An in silico study deduced that asiaticoside hinders early phases of fibrillogenesis via interactions with nucleating amyloid species and slowing the growth phase [121]. Unlike madecassoside and asiaticoside, asiatic acid can cross the BBB to exert rapid neuroprotective actions. Administration of asiatic acid reduced aluminum-stimulated cell death by diminishing mitochondrial dysfunction, oxidative stress and signaling pathways [122] in in vitro and in vivo AD models, moderating the aluminum load, AChE activity, behavioral performance, $\mathrm{A} \beta$ levels and neuroinflammation [123]. Furthermore, asiatic acid exerted a neuroprotective effect against $\mathrm{AlCl}_{3}$-induced cognitive impairments, oxidative stress, cholinergic deficits, tau pathology, $\mathrm{A} \beta$ burden, neuroinflammation and apoptosis [124]. Asiatic acid also demonstrated protective effects against $A \beta_{25-35}$-induced tau protein hyperphosphorylation [125], $C_{2}$-ceramide-induced neuronal cell injury [126], cholesterol-induced cytotoxicity [127], in addition to positively moderating various targets related to $A \beta$ pathways, thus, mitigating $A \beta$ levels in $A D$ brain by diminishing $A \beta$ production and escalating $A \beta$ degradation [128]. Asiatic acid treatment also showed protection against apoptosis, oxidative and glycative stress by reducing ROS and AGE, and downregulating the expression of Bax, NADPH oxidase, RAGE and MAPK [53]. Furthermore, asiatic acid intake was shown to be effective in enhancing memory and learning, as measured by the passive avoidance test [129]; it increased cell pro- 
liferation in the hippocampus and stimulated spatial working memory $[130,131]$, as well as prevented impairment of neurogenesis and spatial memory caused by valproic acid [132].

The neuroprotective effects of madecassoside have also been investigated in a rat model of early-phase Parkinsonism, comprising the administration of 1-methyl-4-phenyl1,2,3,6-tetrahydropyridine (MPTP), a potent neurotoxin that is known to cause dopaminergic neurodegeneration by producing free radicals, leading to oxidative stress. In this model, madecassoside reduced locomotor dysfunction and preserved dopaminergic neurons. Furthermore, madecassoside markedly attenuated the MPTP-induced reduction of striatal dopamine. The MDA content was significantly reduced, while GSH levels, Bcl-2/Bax ratio and expression of BDNF protein were substantially increased in madecassoside-treated groups. These results implied that madecassoside is effective in reducing the early signs of MPTP-induced Parkinsonism [133]. Similar findings were observed in the neuroprotective effect of asiatic acid and asiaticoside against MPTP-induced neurotoxicity [54,134-136]. In a rotenone-induced Parkinson model, asiatic acid protected against mitochondrial injury $[137,138]$ and exerted antiapoptotic effects through a reduction in oxidative stress, maintenance of mitochondrial membrane potential and regulation of expressions of Bcl-2, Bax and caspases [139]. Additionally, the anti-Parkinson effect of asiaticoside was accompanied by an increased expression of proteins involved in phosphoinotiside signaling [140].

Neurite formation is considered to be one of the essential steps in neuro-regeneration, particularly for memory enhancement [113]. The pentacyclic triterpenoids madecassoside, asiaticoside, madecassic acid and asiatic acid are among various natural products that exhibited positive neuroactivity. Immunofluorescent staining studies using the cell line neuro $2 \alpha$ showed madecassoside and asiaticoside to produce a significant elevation in the percentage of neurite-bearing cells and in neurite length; madecassoside and asiaticoside were more potent than madecassic acid and asiatic acid. The activity of the glycosides in promoting neurite outgrowth required sustained activation of ERK1/2 leading to CREB phosphorylation, while neurite lengthening required activation of protein kinase B (Akt) [113].

Neuroinflammation is not only involved in neurodegenerative diseases, but also implicated as a key player in the pathology of cerebral ischemia-reperfusion (I/R) injury [141]. Madecassoside significantly reduced the brain infarct area, resolved the neurological deficit and ameliorated neuronal apoptosis in rats subjected to cerebral I/R. Furthermore, it substantially diminished the MDA and NO levels and heightened antioxidant activity in these animals, as well as decreased the levels of pro-inflammatory cytokines and of NF-kB p65 [141]. In an in vitro ischemic model of oxygen-glucose deprivation followed by reperfusion (OGD/R) in BV2 microglia, madecassoside not only significantly rescued OGD/R-induced cytotoxicity, but also suppressed the secretion of pro-inflammatory cytokines, such as TNF- $\alpha$, IL-1 $\beta$ and IL6. This study concluded that the significant neuroprotective effect of madecassoside against I/R injury both in vivo and in vitro was produced by the attenuation of microglia-mediated neuroinflammation through inhibition of the TLR4/MyD88/NF- $\mathrm{KB}$ signaling pathway [142]. In an in vitro ischemia-hypoxia model asiaticoside increased the neuronal survival rate in a concentration-dependent manner, modulating the expression of apoptotic factors such as Bcl-2, Bax and caspase-3 [143]. Asiaticoside also had a neuroprotective effect against transient cerebral ischemia and reperfusion in a mouse model, by reducing microglial activation, iNOS activity and the level of NO. It also reduced the gene expression of inflammatory cytokines, such as TNF- $\alpha$, IL-1 $\beta$ and IL6 by inhibiting the p38 MAPK signaling pathway [144]. Asiatic acid attenuated cerebral infarction, mitochondrial dysfunction and the induction and activation of matrix metalloproteinase-9 produced by middle cerebral artery occlusion in the rat [51]; similarly, it reduced infarct size, and improved neurological outcome in a mouse model of focal cerebral ischemia, these effects being accompanied by a reduction in BBB permeability [145]. 
As neuroinflammation is a major factor underlying neurodegenerative diseases, attenuating neuroinflammation is an important target of any therapy [111]. In a model of neuroinflammation induced by lipopolysaccharide (LPS), which triggers toll-like receptor 4 activation on the microglia surface, madecassoside markedly reduced the production of ROS, while also concentration-dependently downregulating the gene and protein expression of pro-inflammatory components such as iNOS, COX-2, STAT1 and NF- $\mathrm{kB}$, and increasing the anti-neuroinflammatory heme oxygenase 1 [111]. Likewise, asiatic acid protected against methamphetamine-stimulated neuroinflammation and neurotoxicity via inhibition of NF-KB/STAT3/ERK and mitochondria-mediated apoptosis pathway [146]. Mass accumulation of the endogenous neurotoxin quinolinic acid (QA) causes excessive oxidative stress that leads to neuroinflammation. Treatment with asiatic acid prevented quinolinic acid-induced spatial memory loss and alleviated oxidative stress; these effects were accompanied by improved antioxidant status and a reduction in the dysfunction in mitochondrial oxidative phosphorylation [147].

Beneficial effects have also been reported in other experimental neurological conditions. Asiaticoside and asiatic acid were reported to exhibit antidepressant-like action [148-151], anxiolytic activity [151-153] and antinociceptive effects [154], as well as protection against glutamate-induced excitotoxicity [155,156], kainite-induced seizure [157] and diabetes-induced cognition deficits [158].

\subsection{Cardiovascular Diseases}

Acute myocardial infarction (MI) produces irreversible myocardial injury, resulting in necrosis of a significant portion of the myocardium. Acute MI may be either the nonperfusion type, where the obstruction to blood flow is permanent, or the reperfusion type, in which the obstruction or lack of blood flow is long enough in duration but can be reversed or restored after myocardial cell death occurs. There is a direct correlation between infarct size and prognosis [159]. Since reperfusion is the keystone of treatment for acute MI, there is a need for the advancement of adjunct therapies, which may possibly diminish reperfusion injury and thereby intensify the benefits of reperfusion [160]. Madecassoside showed anti-ischemic effects in vitro and protected rabbit isolated hearts and cardiomyocytes against reperfusion injury [161]. It also protected against vascular endothelial cell injury and increased the coronary flow in the rat isolated heart. The protective effect of madecassoside against myocardial ischemia-reperfusion injury was investigated further in vivo in rats. Madecassoside significantly reduced infarct size in rats subjected to coronary artery ligation followed by reperfusion. The serum levels of CK and LDH, indicators of myocardial injury, were significantly reduced in madecassoside-treated rats, suggesting a protective effect of madecassoside on myocardial cells. There was also improved postischemic ventricular function in rats receiving a high dose of madecassoside. Moreover, madecassoside-treated animals exhibited significantly lower MDA levels, increased SOD activity and lower serum CRP levels compared to the control group [162]. These findings are exactly in accordance with those in a rabbit model of ischemia-reperfusion [161]. Myocardial TNF- $\alpha$ is an autocrine contributor to myocardial contractile dysfunction and cardiomyocyte death in sepsis [163]. Pre-treatment of neonatal rat cardiomyocytes with madecassoside inhibited LPS-induced TNF- $\alpha$ production in a concentration-dependent manner, and, in vivo, significantly reduced the elevation of plasma TNF- $\alpha$ induced by LPS in rats. Investigation of the underlying mechanism showed that madecassoside prevented LPS-induced NF- $\mathrm{KB}$ translocation from cytoplasm into nucleus, and inhibited LPS-induced phosphorylation of ERK1/2 and p38. In vivo studies showed that madecassoside pretreatment delayed the reduction in mean arterial blood pressure, and attenuated the tachycardia induced by LPS [163]. Asiatic acid was also reported to protect against myocardial ischemia/reperfusion injury in an H9c2 cell model, partly via the Akt/GSK-3 $\beta / \mathrm{HIF}-1 \alpha$ pathway [164]. Asiatic acid, among two other triterpenes, protected H9c2 cardiomyocytes against high glucose-induced injury by obliterating oxidative stress and apoptosis [165]. Other studies also reported that the antioxidant and anti-inflammatory properties of asi- 
atic acid were responsible for attenuation of isoproterenol-induced cardiotoxicity [166] and lactate-induced cardiomyocyte apoptosis [167]. Furthermore, asiatic acid augmented survival of AC16 cardiomyocytes against hypoxia-induced apoptosis by regulation of miR-1290/HIF3A/HIF-1 $\alpha$ axis [168]. In a model of heart failure, treatment with asiatic acid preserved cardiac function and inhibited left ventricular remodeling, alleviated cardiomyocyte apoptosis, and reduced interstitial fibrosis and inflammatory responses by inhibiting the mitochondria-dependent apoptotic pathway [169]; it also inhibited phosphorylation of p38 MAPK and ERK 1/2 [170] and reduced NF- $\kappa$ B binding activity [171]. A role for AMPK in asiatic acid-mediated protection against cardiac hypertrophy and fibrosis was suggested by the loss of this protective effect following the depletion of AMPK $\alpha$ [172]. A study also highlighted the efficacy of asiatic acid in blocking IL-1 $\beta$ activated NF- $\mathrm{KB}$ signaling in in vitro and in vivo models [173]. Asiatic acid was also shown to reduce blood pressure and improve vascular function in L-NAME-induced hypertensive rats by enhancing NO bioavailability [174], possibly via upregulation of eNOS protein expression and suppression of inflammation and oxidative stress [175]. In a rat model of the metabolic syndrome (MS) induced by a high-carbohydrate-high-fat (HCHF) diet, asiatic acid supplementation improved the metabolic and cardiovascular complications [176], as well as improved vascular function and reduced activation of the renin-angiotensin system [177]. Asiatic acid could also protect the heart in experimental diabetes in the mouse by attenuating glycative injury and coagulatory disorders [178]. Atherosclerosis, chiefly in coronary artery disease (CAD) or carotid stenosis, is the leading cause of myocardial infarction and stroke, which together are responsible for more than $50 \%$ deaths worldwide [179]. Asiaticoside was shown to impede endothelial hyperpermeability [180], thus possibly disrupting development of early atherosclerotic events [181]. Similar observations were found in studies testing the efficacy of asiatic acid in protecting human aortic endothelial cells [182,183].

\subsection{Lung Diseases}

Pulmonary fibrosis (PF) is a chronic, progressive, irreversible and fatal lung disease [184]. As described above, madecassoside exhibits significant antioxidant and antiinflammatory activities, which are also implicated in PF. An analogue of madecassoside, asiaticoside, was shown to suppress septic lung injury induced by cecal ligation and puncture in mice [185], as well as to inhibit collagen expression and TGF- $\beta$ /Smad signaling pathway activation in keloid fibroblasts [96]. These findings led to an investigation of the effect of madecassoside on bleomycin (BLM)-induced PF in a mouse model. In this study, madecassoside improved pathological changes in the lung and decreased collagen deposition. Expression of $\alpha$-smooth muscle actin and TGF- $\beta 1$ were reduced while phosphorylation of Smad2 and Smad3 (major factors in TGF- $\beta 1$ signaling [96]) in the lung tissues were inhibited. Furthermore, madecassoside attenuated the oxidative damage and inflammation present at the early stage of PF; this was evidenced by a reduction in total leukocytes in the bronchoalveolar lavage fluid, the reduced myeloperoxidase activity and MDA levels, as well as the increased SOD activity and GSH level in the lung tissues [186]. The anti-PF of madecassoside in a bleomycin mouse model was suggested to be mediated by activation of PPAR $\gamma$, leading to subsequent generation of hepatocyte growth factor (HGF) in the colon, from where the upregulated HGF perhaps enters the circulation to reach the lung and impede PF; antagonism of PPAR $\gamma$ almost completely prevented the madecassoside-induced HGF production and its ability to reduce PF [187]. Other studies have shown the effectiveness of HGF in attenuating the fibrotic remodeling in both a rat and mouse PF model $[188,189]$. On the other hand, asiatic acid was reported to ameliorate lung fibrosis and inflammation in BLM-induced PF in mice via TGF- $\beta 1$-induced Smad2/3 and ERK $1 / 2$ signaling pathway inhibition and NLRP3 inflammasome inactivation [190]. 
Acute lung injury (ALI) is an acute inflammatory disorder that causes disruption of the lung endothelial and epithelial barriers [191]. Asiaticoside exhibited protective effects against LPS-induced ALI by lowering the load of IL- 6 and TNF- $\alpha$ while elevating IL-10 secretion [192]; this protective effect was mediated by inhibiting inflammatory cell infiltration and downregulating the NF- $\kappa B$ signaling pathway [193]. Similar findings were obtained in a study investigating the effect of asiatic acid on LPS-induced ALI, where the anti-inflammatory mechanism of asiatic acid was associated with the inhibition of the LPS-induced TLR4 signaling pathway [194]. In a model of ALI produced by spinal cord injury, asiatic acid was reported to activate Nrf2 and inhibit the NLRP3 inflammasome pathway [195]. Asiatic acid was also suggested to have the potential to treat chronic obstructive pulmonary disease (COPD), due to its ability to hinder the pulmonary inflammatory response via suppression of inflammatory mediators and induction of HO-1 [196].

\subsection{Kidney Diseases}

Doxorubicin (DOX) is a chemotherapeutic agent used to treat malignant neoplasms; its use is limited by serious adverse effects, such as nephrotoxicity [197], cardiotoxicity [198] and hepatotoxicity [199], which are in part mediated through free radical formation, oxidative damage and membrane lipid peroxidation [200]. In view of the demonstrated ability of madecassoside to reduce oxidative damage while improving the anti-oxidative enzymes status in various disease models, the effect of madecassoside on DOX-induced renal toxicity was examined in vitro and in vivo. Treatment with madecassoside significantly and concentration-dependently attenuated DOX-induced apoptosis in human proximal tubule cells (HK-2 cells). This effect was associated with the inhibition of DOX-induced ERK phosphorylation, reductions in apoptotic factors (cleaved caspases, apoptotic protease activating factor1, BAX) and an inhibition of iNOS [201]. Moreover, concomitant treatment with madecassoside markedly reduced DOX-induced renal injury in mice, as evidenced by the reduction in serum creatinine and BUN and the preserved structural integrity of the kidneys. These observations suggest that madecassoside could be valuable in preventing/ameliorating DOX-induced toxicity in chemotherapy patients [201].

In a mouse model of obstructive nephropathy, asiatic acid intake significantly ameliorated tubulointerstitial fibrosis by suppressing tubular injury, fibroblast activation and ECM accumulation mediated via Smad7-dependent TGF- $\beta 1$ signaling [202]. Asiatic acid was identified to function as a Smad7 agonist that inhibits Smad3 signaling [203]. Moreover, pre-treatment with asiatic acid inhibited NF- $\mathrm{kB}$ activation and inflammatory responses, possibly from Smad7 upregulation, in cisplatin-induced acute kidney injury [204].

\subsection{Liver Diseases}

Acute liver failure (ALF) is a life-threatening condition with a high mortality rate worldwide. It is manifested by hepatic dysfunction, abnormal liver biochemical parameters and coagulopathy [205]. The onset of ALF is an inflammation mediated by hepatocellular injury process that closely resembles the innate immune response induced by exposure to LPS (endotoxin). LPS combined with D-GaIN acts as a hepatotoxic or liver damaging agent that is typically used to induce ALF in experimental models [206]. Pre-treatment of mice with madecassoside markedly suppressed the LPS/DGalN-induced increases in the serum concentrations of ALT and AST, and preserved hepatic integrity, protecting against hemorrhage and cellular necrosis. Madecassoside pre-treatment significantly reduced the LPS/DGalN-mediated increase in the hepatic levels of the inflammatory cytokines IL- $1 \beta$, IL-6 and TNF- $\alpha$, while increasing levels of the antioxidant enzymes SOD, catalase and glutathione peroxidase. These effects were associated with inhibition by madecassoside of the phosphorylation of p38 MAPK and NF-KB [207]. The effects of asiaticoside on ALF were also tested in a similar model. Treatment with asiaticoside improved liver function, alleviated liver injury and attenuated apoptosis induced by LPS/DGalN, possibly via the inhibition of the expression of TNF- $\alpha$ and MAPKs [208]. The protective effects of asiatic 
acid against LPS/DGalN-induced injury was associated with the inhibition of the cellular redox-regulated $\mathrm{LTC}_{4} \mathrm{~S}$ expression pathway [209].

Liver fibrosis occurs when excessive collagen and extracellular matrix deposit in the liver. Liver fibrosis can advance to liver cirrhosis, eventually causing liver failure and ultimately death [210]. Asiatic acid was discovered to protect against carbon tetrachloride $\left(\mathrm{CCl}_{4}\right)$-induced liver fibrosis via multiple mechanisms; these include the inhibition of TGF- $\beta$ /Smad signaling pathways in in vivo and in vitro models [211], regulation of the PI3K/AKT/mTOR and Bcl-2/Bax signaling pathways [212] and suppression of NF$\kappa \mathrm{B} / \mathrm{I} \kappa \mathrm{B} \alpha$ and JAK1/STAT3 signaling [213].

Intragastric administration of asiatic acid was shown to protect the liver against ethanol-induced hepatotoxicity by ameliorating oxidative stress and inhibiting Kupffer cell activation, via diminishing the expression of TLR4, CD14 and MyD88 [214]. In addition, supplementation with asiatic acid improved insulin resistance and attenuated hepatic oxidative and inflammatory injury in mice fed a high-fat diet [215]. Pre-treatment with asiatic acid reportedly can protect against I/R-induced liver injury in rats and anoxia/reoxygenation (A/R)-induced injury in isolated rat liver mitochondria [216]. This is in agreement with a previous study demonstrating that treatment with asiatic acid induced partial uncoupling of mitochondria and thus protected mitochondrial function [217]. Moreover, asiatic acid may alleviate hepatic I/R injury through mitigation of Kupffer cells activation via the PPAR $\gamma$ /NLRP3 inflammasome signaling pathway [218]. On the other hand, asiatic acid demonstrated a protective effect against DOX-induced liver toxicity in a rat model in a dose-dependent manner through the modulation of Nrf2 translocation, suggesting its use as an organ-protective adjuvant in DOX treatment [219].

\subsection{Anticancer Actions}

Cancer chemoprevention is presently the favored area in current research trends [220]. Dysregulation of growth factor pathways is a known contributor to the development of hepatocellular carcinoma (HCC) [221]. Binding of HGF to its receptor promotes proliferation, survival and migration in a variety of cancer cells, including HCC [222]. Treatment of HGF-induced hepatocellular carcinoma (HCC) cell lines (HepG2 and SMMC-77 cells) with madecassoside significantly reduced HGF-induced proliferative and invasive responses. These effects of madecassoside were associated with the downregulation of the expression of COX-2 and $\mathrm{PGE}_{2}$, and inhibition of p-cMET, p-ERK1/2 and PKC activity. This suggested that madecassoside could be an effective therapeutic drug to reduce HGF-induced tumor growth and metastasis in HCC [223]. Meanwhile, madecassic acid has been showed to exert antitumor activity by inducing cancer cell apoptosis and improving immunomodulation in a mouse colon cancer model [224]. Asiaticoside has demonstrated effectiveness in both in vitro and in vivo breast cancer models, significantly reducing TNF- $\alpha$ and IL-1 $\beta$ expressions, inducing apoptosis and enhancing antitumor activity [220,225]. In addition, asiaticoside counteracted proliferation, migration and invasion of drug-resistant multiple myeloma cells by triggering autophagy via STAT-3 pathway inhibition [226]. Unlike madecassoside, madecassic acid and asiaticoside, asiatic acid has been researched extensively for its antitumor effect. For instance, asiatic acid has been successively reported to possess strong cell growth inhibition in hepatoma [227-229], melanoma [230,231], glioblastoma [232-234], multiple myeloma [235], colon [236-240], in ovarian [241], breast [242], lung [243,244], and prostate cancer [245], as well as in leukemia [246].

\subsection{Diabetes}

Diabetes mellitus (DM) is a widespread disease worldwide, especially in Asia [247]. Centella asiatica has been used as a remedy for DM in Ayurvedic traditional medicine [248,249]. A study reported that asiaticoside exhibited significant antidiabetic activity in alloxan-induced diabetic mice, most likely by stimulating pancreatic $\beta$ cells to secrete insulin [247]. In streptozotocin (STZ)-induced diabetic rats, asiatic acid exhibited antihyperlipidemic and antidiabetic effects; here, it decreased blood glucose, increased plasma 
insulin concentrations and reversed changes in key carbohydrate-metabolizing enzyme levels [250], as well as prevented lipid peroxidation and increased antioxidant status [251,252]. Asiatic acid was postulated to exert its antihyperglycemic activity by enhancing glucose uptake into skeletal muscle in insulin-deficient STZ diabetic rats via the PI3K-Akt signaling pathway [253]. Asiatic acid also demonstrated lipid and glucose lowering effects in $\mathrm{db} / \mathrm{db}$ mice via PI3K/Akt/GSK-3 $\beta$ to accelerate glycogen synthesis [254]. Asiatic acid was also proposed to mitigate hyperglycemia by preserving and restoring beta cell mass and function [255], reducing islet fibrosis formation and reversing the over-expression of fibronectin [256]. Madecassic acid was shown to improve glycemic control, lower plasma lipids and attenuate oxidative and inflammatory stress in streptozotocin-induced diabetes in mice [257]. Madecassic acid also reduced insulin resistance and endothelial dysfunction in mice made obese using a high-fat diet [258]. A study conducted recently in our laboratory has demonstrated the efficacy of madecassoside in protecting $\beta$ cells both in vivo in STZ-diabetic rats and in vitro [259].

Asiatic acid and asiaticoside may also be effective in ameliorating the complication of diabetes. Asiatic acid could protect against diabetic nephropathy in rats with STZinduced diabetes [260]. In vitro, asiaticoside was shown to protect cochlear hair cells from high glucose-induced injury by increasing antioxidative activity and suppressing the AGEs/RAGE/NF-kB pathway [261].

Table 1. A summary of pharmacological activities of all compounds published from year 2015 to 2021.

\begin{tabular}{|c|c|c|c|}
\hline Condition & Compound & Outcome & Reference \\
\hline \multirow{5}{*}{ Skin related conditions } & \multirow{3}{*}{ Asiaticoside } & Promote cell proliferation and collagen synthesis & [79] \\
\hline & & Accelerate wound healing, suppress apoptosis & [85] \\
\hline & & Hinder keloid fibroblast's invasive growth & [95] \\
\hline & \multirow{2}{*}{ Madecassoside } & Anti-oxidative, attenuate mitochondrial damage, promote autophagy & [87] \\
\hline & & Decrease dermal inflammation, reduced keratinocyte proliferation & [89] \\
\hline \multirow{2}{*}{ Rheumatoid arthritis } & \multirow{2}{*}{ Madecassoside } & Increase systemic levels of IL-10 & [106] \\
\hline & & Prevent NF- $k \mathrm{~B}$ translocation and phosphorylation & {$[110]$} \\
\hline \multirow{25}{*}{ Neurodegenarative diseases } & \multirow{8}{*}{ Asiaticoside } & $\begin{array}{l}\text { Reduce learning and memory function impairment, A } \beta \text { build-up, IL- } 6 \text { and } \\
\text { TNF- } \alpha \text { levels }\end{array}$ & [117] \\
\hline & & Attenuate $A \beta_{1-42 \text {-induced cytotoxicity and apoptosis }}$ & [118] \\
\hline & & Promote cell proliferation, inhibit apoptosis & [120] \\
\hline & & Hinder early phase of fibrillogenesis & [121] \\
\hline & & Modulate expression of apoptotic factors & [143] \\
\hline & & Antidepressant-like action & {$[149,150]$} \\
\hline & & Antinociceptive effects & [154] \\
\hline & & Attenuate diabetes induced cognitive deficits & [158] \\
\hline & \multirow{15}{*}{ Asiatic acid } & Diminish mitochondrial dysfunction, oxidative stress & [122] \\
\hline & & $\begin{array}{c}\text { Regulate aluminium load, } \mathrm{AChE} \text { activity, behavioural performance, } \mathrm{A} \beta \\
\text { levels and neuroinflammation }\end{array}$ & {$[123]$} \\
\hline & & Protect against oxidative stress, cholinergic deficits, tau pathology, apoptosis & [124] \\
\hline & & Protect against $\mathrm{A} \beta_{25-35}$ induced tau protein hyperphosphorylation & [125] \\
\hline & & Protect against cholesterol-induced cytotoxicity & [127] \\
\hline & & Increase hippocampal cell proliferation, stimulate spatial working memory & {$[130,131]$} \\
\hline & & Prevent neurogenesis and spatial memory impairment & [132] \\
\hline & & Reduce MDA, increase GSH content & [136] \\
\hline & & Protect against mitochondrial injury & [138] \\
\hline & & Reduce oxidative stress, maintain mitochondrial membrane potential & [139] \\
\hline & & Increased proteins expression involved in phosphoinotiside signalling & [140] \\
\hline & & Protect against neuroinflammation and neurotoxicity & [146] \\
\hline & & Prevent spatial memory loss and alleviate oxidative stress & [147] \\
\hline & & Antidepressant-like action, anxiolytic activity & [151] \\
\hline & & Decrease hippocampal inflammatory and oxidative stress & [157] \\
\hline & \multirow[t]{2}{*}{ Madecassoside } & $\begin{array}{c}\text { Reduce ROS production, downregulate pro-inflammatory components gene } \\
\text { and protein expression }\end{array}$ & {$[111]$} \\
\hline & & Attenuate microglia-mediated neuroinflammation & [142] \\
\hline
\end{tabular}


Table 1. Cont.

\begin{tabular}{|c|c|c|c|}
\hline Condition & Compound & Outcome & Reference \\
\hline \multirow{13}{*}{ Cardiovascular diseases } & \multirow{11}{*}{ Asiatic acid } & Attenuate isoproterenol-induced cardiotoxicity & [166] \\
\hline & & Attenuate lactate-induced cardiomyocyte apoptosis & [167] \\
\hline & & Protect against hypoxia-induced apoptosis & [168] \\
\hline & & $\begin{array}{c}\text { Preserve cardiac function, inhibit left ventricular remodelling, alleviate } \\
\text { cardiomyocyte apoptosis }\end{array}$ & [169] \\
\hline & & Inhibit p38 MAPK and ERK $1 / 2$ phosphorylation & [170] \\
\hline & & Protect against cardiac hypertrophy and fibrosis & [172] \\
\hline & & Block IL-1 $\beta$ activated NF- $\mathrm{kB}$ signaling & [173] \\
\hline & & Suppress inflammation and oxidative stress & [175] \\
\hline & & Improve vascular function & [177] \\
\hline & & Attenuate glycative injury and coagulatory disorders & [178] \\
\hline & & Protect human aortic endothelial cells & {$[182,183]$} \\
\hline & \multirow{2}{*}{ Asiaticoside } & Impede endothelial hyperpermeability & [183] \\
\hline & & Disrupt development of early atherosclerotic events & [181] \\
\hline \multirow{6}{*}{ Lung diseases } & Madecassoside & Activate PPAR $\gamma$, generate HGF, impede pulmonary fibrosis & [187] \\
\hline & \multirow{4}{*}{ Asiatic acid } & Ameliorate lung fibrosis and inflammation & [190] \\
\hline & & Inhibit TLR4 signaling pathway & [194] \\
\hline & & Activate Nrf2 and inhibit NLRP3 inflammasome pathway & [195] \\
\hline & & Suppress inflammatory mediators and induction of HO-1 & [196] \\
\hline & Asiaticoside & $\begin{array}{l}\text { Inhibiting inflammatory cell infiltration and downregulate the NF-kB } \\
\text { signaling pathway }\end{array}$ & [193] \\
\hline \multirow{3}{*}{ Kidney diseases } & Madecassoside & Inhibit ERK phosphorylation, reduce apoptotic factors, inhibit iNOS & [201] \\
\hline & \multirow{2}{*}{ Asiatic acid } & Inhibits Smad3 signaling & [203] \\
\hline & & Inhibit NF- $\mathrm{kB}$ activation and inflammatory responses & [204] \\
\hline \multirow{5}{*}{ Liver diseases } & Madecassoside & Reduce inflammatory cytokines, increase antioxidant enzymes & [207] \\
\hline & \multirow{4}{*}{ Asiatic acid } & Regulate PI3K/AKT/mTOR and Bcl-2/Bax signaling pathways & [212] \\
\hline & & Suppress NF-kB/IкB $\alpha$ and JAK1/STAT3 signaling & [213] \\
\hline & & Protect mitochondrial function & [216-218] \\
\hline & & Organ protective adjuvant & [219] \\
\hline \multirow{7}{*}{ Cancer } & Madecassoside & Downregulate expression of COX-2 and $\mathrm{PGE}_{2}$ & [223] \\
\hline & Asiaticoside & Autophagy induction, inhibit cell migration and invasion & [226] \\
\hline & \multirow{5}{*}{ Asiatic acid } & Inhibit cancerous cell growth in glioblastoma & {$[232,234]$} \\
\hline & & Reduce inflammation, cell proliferation and induce apoptosis in & {$[236,237,239]$} \\
\hline & & $\begin{array}{c}\text { colon cancer } \\
\text { Suppress PI3K/AKT/mTOR signaling }\end{array}$ & [241] \\
\hline & & Inhibits lung cancer cell growth & [243] \\
\hline & & Apoptosis of human leukemia cells & [246] \\
\hline \multirow{7}{*}{ Diabetes } & \multirow{4}{*}{ Asiatic acid } & Enhance glucose uptake into skeletal muscle & [253] \\
\hline & & Lower lipid and glucose levels & [254] \\
\hline & & Reduce islet fibrosis formation & [256] \\
\hline & & Protect against diabetic nephropathy & [260] \\
\hline & \multirow{2}{*}{ Madecassic acid } & $\begin{array}{c}\text { Improve glycemic control, lower plasma lipids, attenuate oxidative and } \\
\text { inflammatory stress }\end{array}$ & [257] \\
\hline & & Reduce insulin resistance and endothelial dysfunction & [258] \\
\hline & Asiaticoside & Protect cochlear hair cells & [261] \\
\hline
\end{tabular}

\section{Conclusions}

The use of natural compounds extracted from plants has attracted the interest of scientific and medical communities, due to their accessibility as well as their lower cost in comparison with synthetic drugs. Centella asiatica has been widely used in Ayurvedic and Chinese traditional medicines for a century as a therapy in many cases, such as skin diseases, neurological disease, cardiac disease, diabetes, cancer and many more. The bioactive pentacyclic triterpenoid compounds of $C$. asiatica have been widely studied and reported to possess various biological properties. Among them, madecassoside, the main bioactive saponin of $C$. asiatica has been shown experimentally to have wound healing, scar healing, cell growth-promoting, neuroprotective, cardioprotective, anti-oxidative and 
anti-inflammatory properties. There are many more niche areas that can be investigated for its therapeutic effect, given its consistent anti-oxidative and anti-inflammatory properties. Madecassoside exerts its therapeutic effect through various mechanisms and cell signaling pathways. Recognition and understanding of the pathways and mediators involved are fundamental in illuminating the therapeutic potential, along with determination of the drug's toxicity. In summary, this review demonstrates that madecassoside could be a significant complementary medicine for the prevention and treatment of various disorders, owing to its natural origin and affordable cost compared to synthetically produced drugs. Further studies of this triterpenoid are warranted.

Author Contributions: Conceptualization, S.C.T. and M.C.; writing-original draft preparation, S.C.T.; writing-review and editing, S.C.T., M.C., S.K.B. and D.K.C. All authors have read and agreed to the published version of the manuscript.

Funding: A doctoral research on madecassoside was carried out at International Medical University, Kuala Lumpur, Malaysia by the author S.C.T. and the research was funded by Fundamental Research Grant Scheme (FRGS) of the Ministry of Higher Education, Malaysia and bears the grant number FRGS/2/2014/SKK03/IMU/03/1.

Acknowledgments: The authors are utmost grateful to Brian L. Furman from Strathclyde Institute of Pharmacy and Biomedical Sciences (Glasgow, U.K.) for his guidance in reviewing this paper, and to Ministry of Higher Education, Malaysia for awarding the research grant.

Conflicts of Interest: The authors declare no conflict of interest.

$\begin{array}{ll}\text { Abbreviations } & \\ \text { CA } & \text { Centella asiatica } \\ \text { TLC } & \text { Thin layer chromatography } \\ \text { TLC-MS } & \text { Thin layer chromatography-mass spectrometry } \\ \text { UVS } & \text { Ultraviolet-visible spectroscopy } \\ \text { HPLC } & \text { High performance liquid chromatography } \\ \text { HPTLC } & \text { High performance thin layer chromatography } \\ \text { HPLC-ESI-MS } & \text { HPLC-electrospray ionisation-mass spectrometry } \\ \text { HPLC-UV } & \text { HPLC-ultraviolet } \\ \text { HPLC-ELSD } & \text { HPLC-paired with evaporative light scattering detector } \\ \text { HPAEC-PAD } & \text { High-performance anion-exchange chromatography combined with } \\ & \text { pulsed amperometric detection } \\ \text { HPLC-PAD } & \text { HPLC- pulsed amperometric detection } \\ \text { ELISA } & \text { Enzyme-linked immunosorbent assay } \\ \text { cmax } & \text { Maximum plasma concentration } \\ \text { BBB } & \text { Blood brain barrier } \\ \text { t1/2 } & \text { Half-life } \\ \text { AUC0-24 } & \text { Area under plasma concentration-time curve from 0-24 h } \\ \text { LD50 } & \text { Median lethal dose } \\ \text { Vd/f } & \text { Apparent volume of distribution } \\ \text { Ke } & \text { Elimination rate constant } \\ \text { CIA } & \text { Collagen-induced arthritis } \\ \text { HUVEC } & \text { Human umbilical vein endothelial cell } \\ \text { MAPK } & \text { Mitogen activated protein kinases } \\ \text { VEGF } & \text { Vascular endothelial growth factor } \\ \text { MCP-1 } & \text { Monocyte chemoattractant protein-1 } \\ \text { UV } & \text { Ultraviolet } \\ \text { UVA } & \text { Ultraviolet A } \\ \text { UVB } & \text { Ultraviolet B } \\ \text { PAR-2 } & \text { Protease activator receptor 2 } \\ \text { COX-2 } & \text { Cyclooxygenase 2 } \\ \text { PGE2 } & \text { Prostaglandin E2 } \\ \text { PGF2 } \alpha & \text { Prostaglandin F2 alpha } \\ & \end{array}$




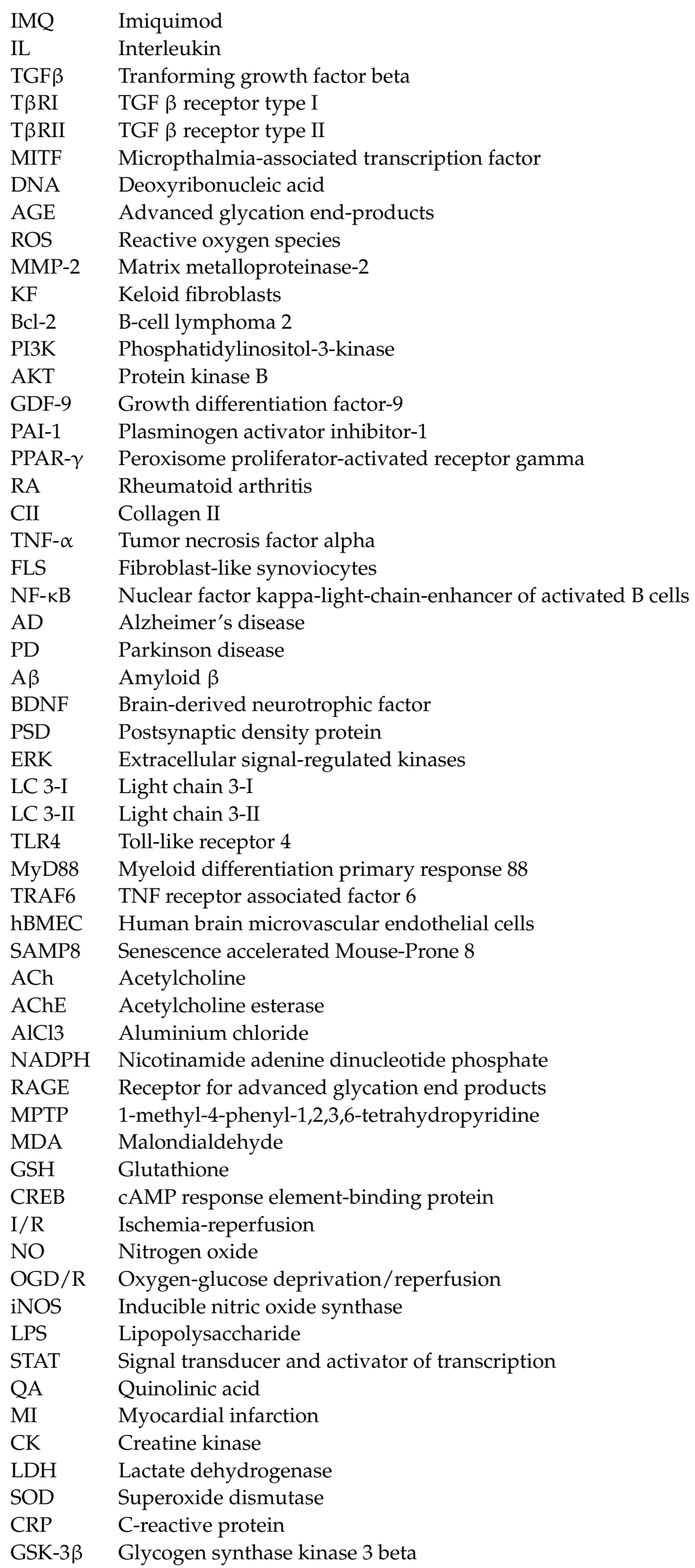




$\begin{array}{ll}\text { HIF-1 } \alpha & \text { Hypoxia-inducible Factor 1-alpha } \\ \text { HIF3A } & \text { Hypoxia-inducible Factor 3-alpha } \\ \text { AMPK } & 5^{\prime} \text { adenosine monophosphate-activated protein kinase } \\ \text { L-NAME } & \text { N(gamma)-nitro-L-arginine methyl ester } \\ \text { eNOS } & \text { Endothelial nitric oxide synthase } \\ \text { MS } & \text { Metabolic syndrome } \\ \text { HCHF } & \text { High carbohydrate high fat } \\ \text { CAD } & \text { Coronary artery disease } \\ \text { PF } & \text { Pulmonary fibrosis } \\ \text { BLM } & \text { Bleomycin } \\ \text { HGF } & \text { Hepatocyte growth factor } \\ \text { ALI } & \text { Acute lung injury } \\ \text { COPD } & \text { Chronic obstructive pulmonary disease } \\ \text { HO-1 } & \text { Heme oxygenase-1 } \\ \text { DOX } & \text { Doxorubicin } \\ \text { HK-2 } & \text { Human proximal tubule cells } \\ \text { BUN } & \text { Blood urea nitrogen } \\ \text { ECM } & \text { Extracellular matrix } \\ \text { ALF } & \text { Acute liver failure } \\ \text { D-GaIN } & \text { D-galactosamine } \\ \text { ALT } & \text { Alanine aminotransferase } \\ \text { AST } & \text { Aspartate aminotransferase } \\ \text { LTC4S } & \text { Leukotriene C4 synthase } \\ \text { CCl4 } & \text { Carbon tetrachloride } \\ \text { mTOR } & \text { Mammalian target of rapamycin } \\ \text { IKB } \alpha & \text { Inhibitor of nuclear factor kappa B } \\ \text { CD14 } & \text { Cluster of differentiation 14 } \\ \text { A/R } & \text { Anoxia/reoxygenation } \\ \text { Nrf2 } & \text { Nuclear transcription factor } \\ \text { HCC } & \text { Hepatocellular carcinoma } \\ \text { PKC } & \text { Protein kinase C } \\ \text { DM } & \text { Diabetes mellitus } \\ \text { STZ } & \text { Streptozotocin } \\ & \end{array}$

\section{References}

1. Nurlaily, A.; Noor, B.A.R.; Musalmah, M. Comparative Antioxidant and Anti-inflammatory Activity of Different Extracts of Centella asiatica (L.) Urban and Its Active Compounds, Asiaticoside and Madecassoside. Med. Health 2012, 7, 62-72.

2. Aziz, Z.A.; Davey, M.R.; Power, J.B.; Anthony, P.; Smith, R.M.; Lowe, K.C. Production of asiaticoside and madecassoside in Centella asiatica in vitro and in vivo. Biol. Plant. 2007, 51,34-42. [CrossRef]

3. Chandrika, U.G.; Kumara, P.A.P. Gotu Kola (Centella asiatica): Nutritional properties and plausible health benefits. Adv. Food Nutr. Res. 2015, 76, 125-157.

4. Tassanawat, P.; Putalun, W.; Yusakul, G.; Sritularak, B.; Juengwatanatrakul, T.; Tanaka, H. Production of polyclonal antibody against madecassoside and development of immunoassay methods for analysis of triterpene glycosides in Centella asiatica. Phytochem. Anal. 2013, 24, 256-262. [CrossRef]

5. Kwon, H.; Park, J.; Kim, G.; Park, Y. Determination of madecassoside and asiaticoside contents of C. asiatica leaf and C. asiatica-containing ointment and dentifrice by HPLC-coupled pulsed amperometric detection. Microchem. J. 2010, 98, 115-120. [CrossRef]

6. Han, W.J.; Xia, Y.F.; Dai, Y. Development and validation of high-performance liquid chromatography/electrospray ionization mass spectrometry for assay of madecassoside in rat plasma and its application to pharmacokinetic study. Biomed. Chromatogr. 2012, 26, 26-32. [CrossRef] [PubMed]

7. Thomas, M.T.; Kurup, R.; Johnson, A.J.; Chandrika, S.P.; Mathew, P.J.; Dan, M.; Baby, S. Elite genotypes/chemotypes, with high contents of madecassoside and asiaticoside, from sixty accessions of Centella asiatica of south India and the Andaman Islands: For cultivation and utility in cosmetic and herbal drug applications. Ind. Crop. Prod. 2010, 32, 545-550. [CrossRef]

8. Jia, G.; Lu, X. Enrichment and purification of madecassoside and asiaticoside from Centella asiatica extracts with macroporous resins. J. Chromatogr. A 2008, 1193, 136-141. [CrossRef]

9. Kai, G.; Pan, J.; Yuan, C.; Yuan, Y. Separation of Madecassoside and Madecassic Acid Isomers by High Performance Liquid Chromatography Using $\beta$-Cyclodextrin as Mobile Phase Additive. Bull. Korean Chem. Soc. 2008, 29, 551-554. [CrossRef] 
10. Hengjumrut, P.; Anukunwithaya, T.; Tantisira, M.H.; Tantisira, B.; Khemawoot, P. Comparative pharmacokinetics between madecassoside and asiaticoside presented in a standardised extract of Centella asiatica, ECa 233 and their respective pure compound given separately in rats. Xenobiotica 2018, 48, 18-27. [CrossRef]

11. Khemawoot, P.; Hengjumrut, P.; Anukunwithaya, T.; Chang, L.C.; Wongwiwatthananukit, S.; Tantisira, M.H. Comparison of the Pharmacokinetic Profiles of a Standardized Extract of Centella asiatica and A Mixture of Madecassoside and Asiaticoside in Rats. PMIO 2018, 5, e39-e47. [CrossRef]

12. Jana, U.; Sur, T.K.; Maity, L.N.; Debnath, P.K.; Bhattacharyya, D. A clinical study on the management of generalized anxiety disorder with Centella asiatica. Nepal Med. Coll. J. 2010, 12, 8-11. [PubMed]

13. Bradwejn, J.; Zhou, Y.; Koszycki, D.; Shlik, J. A double-blind, placebo-controlled study on the effects of Gotu Kola (Centella asiatica) on acoustic startle response in healthy subjects. J. Clin. Psychopharmacol. 2000, 20, 680-684. [CrossRef] [PubMed]

14. Rao-Appa, M.; Srinivasan, K.; Rao, K. Effect of mandookaparni (Centella asiatica) on the mentally retarded children. J. Res. Indian Med. 1973, 8, 9.

15. Wattanathorn, J.; Mator, L.; Muchimapura, S.; Tongun, T.; Pasuriwong, O.; Piyawatkul, N.; Yimtae, K.; Sripanidkulchai, B.; Singkhoraard, J. Positive modulation of cognition and mood in the healthy elderly volunteer following the administration of Centella asiatica. J. Ethnopharmacol. 2008, 116, 325-332. [CrossRef] [PubMed]

16. Tiwari, S.; Singh, S.; Patwardhan, K.; Gehlot, S.; Gambhir, I. Effect of Centella asiatica on mild cognitive impairment (MCI) and other common age-related clinical problems. Dig. J. Nanomater. Biostruct. 2008, 3, 215-220.

17. Incandela, L.; Belcaro, G.; Nicolaides, A.; Cesarone, M.; De Sanctis, M.; Corsi, M.; Bavera, P.; Ippolito, E.; Griffin, M.; Geroulakos, G. Modification of the Echogenicity of Femoral Plaques after Treatment with Total Triterpenic Fraction of Centella aslatica: A Prospective, Randomized, Placebo-Controlled Trial. Angiology 2001, 52, S69-S73. [CrossRef]

18. Cesarone, M.; Belcaro, G.; Rulo, A.; Griffin, M.; Ricci, A.; Ippolito, E.; De Sanctis, M.; Incandela, L.; Bavera, P.; Cacchio, M. Microcirculatory effects of total triterpenic fraction of Centella asiatica in chronic venous hypertension: Measurement by laser Doppler, TcPO2-CO2, and leg volumetry. Angiology 2001, 52, S45-S48. [CrossRef]

19. Cesarone, M.; Belcaro, G.; De Sanctis, M.; Incandela, L.; Cacchio, M.; Bavera, P.; Ippolito, E.; Bucci, M.; Griffin, M.; Geroulakos, G. Effects of the total triterpenic fraction of Centella asiatica in venous hypertensive microangiopathy: A prospective, placebocontrolled, randomized trial. Angiology 2001, 52, S15-S18. [CrossRef]

20. Belcaro, G.V.; Grimaldi, R.; Guidi, G. Improvement of capillary permeability in patients with venous hypertension after treatment with TTFCA. Angiology 1990, 41, 533-540. [CrossRef]

21. Cesarone, M.; Incandela, L.; De Sanctis, M.; Belcaro, G.; Bavera, P.; Bucci, M.; Ippolito, E. Evaluation of treatment of diabetic microangiopathy with total triterpenic fraction of Centella asiatica: A clinical prospective randomized trial with a microcirculatory model. Angiology 2001, 52, S49-S54. [CrossRef]

22. Incandela, L.; Belcaro, G.; Cesarone, M.; De Sanctis, M.; Nargi, E.; Patricelli, P.; Bucci, M. Treatment of diabetic microangiopathy and edema with total triterpenic fraction of Centella asiatica: A prospective, placebo-controlled randomized study. Angiology 2001, 52, S27-S31. [CrossRef]

23. Cesarone, M.R.; Laurora, G.; De Sanctis, M.T.; Incandela, L.; Grimaldi, R.; Marelli, C.; Belcaro, G. The microcirculatory activity of Centella asiatica in venous insufficiency. A double-blind study. Minerva Cardioangiol. 1994, 42, 299-304.

24. Pointel, J.; Boccalon, H.; Cloarec, M.; Ledevehat, C.; Joubert, M. Titrated extract of Centella asiatica (TECA) in the treatment of venous insufficiency of the lower limbs. Angiology 1987, 38, 46-50. [CrossRef] [PubMed]

25. Chaudhuri, S.; Ghosh, S.; Chakraborty, T.; Kundu, S.; Hazra, S. Use of a common Indian herb "mandukaparni" in the treatment of leprosy. J. Indian Med. Assoc. 1978, 70, 177-180. [PubMed]

26. Darnis, F.; Orcel, L.; De Saint-Maur, P.P.; Mamou, P. Use of a titrated extract of Centella asiatica in chronic hepatic disorders (author's transl). Sem. Hop. 1979, 55, 1749-1750. [PubMed]

27. Rhee, J.; Choi, K. Clinical effect of the titrated extract of Centella asiatica (madecassol) on peptic ulcer. Korean J. Gastroenterol. 1981, $13,35-40$.

28. Cho, K. Clinical experiences of madecassol (Centella asiatica) in the treatment of peptic ulcer. Korean J. Gastroenterol. 1981, 13, 49-56.

29. Shin, H.; Choi, I.; Lee, M.; Park, K. Clinical trials of madecassol (Centella asiatica) on gastrointestinal ulcer patients. Korean J. Gastroenterol. 1982, 14, 49-56.

30. Wu, F.; Bian, D.; Xia, Y.; Gong, Z.; Tan, Q.; Chen, J.; Dai, Y. Identification of Major Active Ingredients Responsible for Burn Wound Healing of Centella asiatica Herbs. Evid. Based. Complement. Altern. Med. 2012, 2012, 848093. [CrossRef]

31. Plengmuankhae, W.; Tantitadapitak, C. Low temperature and water dehydration increase the levels of asiaticoside and madecassoside in Centella asiatica (L.) Urban. S. Afr. J. Bot. 2015, 97, 196-203. [CrossRef]

32. Xing, H.; Su, B.; Wang, Y.; Yang, Y.; Ren, Q.; Xiao, W.; Lu, X. Separation and Determination of Asiaticoside, Asiaticoside-B and Madecassoside in Centella asiatica Total Triterpenoid Saponins by HPLC. J. Liq. Chromatogr. Rel. Technol. 2009, 32, 1891-1900. [CrossRef]

33. Gupta, A.; Verma, S.; Kushwaha, P.; Srivastava, S.; Aks, R. Quantitave Estimation of Asiatic acid, Asiaticoside \& Madecassoside in two accessions of Centella asiatica (L) Urban for Morpho-chemotypic variation. Pharm. Res. 2014, 48, 75-79.

34. Pan, J.; Kai, G.; Yuan, C.; Jin, R. Separation and Determination of the Structural Isomers of Madecassoside by HPLC Using $\hat{\mathrm{I}}^{2}$-Cyclodextrin as Mobile Phase Additive. Chromatographia 2007, 66, 121-123. [CrossRef] 
35. Leng, D.D.; Han, W.J.; Rui, Y.; Dai, Y.; Xia, Y.F. In vivo disposition and metabolism of madecassoside, a major bioactive constituent in Centella asiatica (L.) Urb. J. Ethnopharmacol. 2013, 150, 601-608. [CrossRef] [PubMed]

36. Bonfill, M.; Mangas, S.; Cusido, R.M.; Osuna, L.; Pinol, M.T.; Palazon, J. Identification of triterpenoid compounds of Centella asiatica by thin-layer chromatography and mass spectrometry. Biomed. Chromatogr. 2006, 20, 151-153. [CrossRef]

37. Diallo, B.; Vanhaelen-Fastré, R.; Vanhaelen, M. Direct coupling of high-speed counter-current chromatography to thin-layer chromatography: Application to the separation of asiaticoside and madecassoside from Centella asiatica. J. Chromatogr. A 1991, 558, 446-450. [CrossRef]

38. Du, Q.; Jerz, G.; Chen, P.; Winterhalter, P. Preparation of Ursane Triterpenoids from Centella asiatica Using High Speed Countercurrent Chromatography with Step-Gradient Elution. J. Liq. Chromatogr. Rel. Technol. 2004, 27, 2201-2215. [CrossRef]

39. Rai, P.; Mishra, S. Development of a simple and sensitive spectrophotometric method for the simultaneous determination of asiaticoside and wedelolactone in a polyherbal formulation. Pharmacogn. Mag. 2007, 3, 47-51.

40. Randriamampionona, D.; Diallo, B.; Rakotoniriana, F.; Rabemanantsoa, C.; Cheuk, K.; Corbisier, A.; Mahillon, J.; Ratsimamanga, S.; El Jaziri, M. Comparative analysis of active constituents in Centella asiatica samples from Madagascar: Application for ex situ conservation and clonal propagation. Fitoterapia 2007, 78, 482-489. [CrossRef]

41. Rafamantanana, M.H.; Rozet, E.; Raoelison, G.E.; Cheuk, K.; Ratsimamanga, S.U.; Hubert, P.; Quetin-Leclercq, J. An improved HPLC-UV method for the simultaneous quantification of triterpenic glycosides and aglycones in leaves of Centella asiatica (L.) Urb (APIACEAE). J. Chromatogr. B Anal. Technol. Biomed. Life Sci. 2009, 877, 2396-2402. [CrossRef]

42. Zhang, F.L.; Wei, Y.J.; Zhu, J.; Gong, Z.N. Simultaneous quantitation of three major triterpenoid glycosides in Centella asiatica extracts by high performance liquid chromatography with evaporative light scattering detection. Biomed. Chromatogr. 2008, 22, 119-124. [CrossRef] [PubMed]

43. Gupta, A.P.; Gupta, M.M.; Kumar, S. HPTLC of asiaticoside in Centella asiatica. J. Indian Chem. Soc. 1999, 76, 321-322.

44. Singh, B.; Tyagi, A.; De, J.; Agrawal, S. HPTLC determination of asiaticoside in Centella asiatica (Linn.). Indian Drugs 2005, 42, 87-89.

45. Benny, M.; Antony, B. Estimation of asiaticoside by HPTLC. Indian J. Nat. Prod. 2005, 21, 22-23.

46. Zhang, L.L.; Wang, H.S.; Yao, Q.Q.; Luan, Y.; Wang, X.L. Determination of asiaticoside and madecassoside in Centella asiatica (L.) Urb. by RP-HPLC. Chin. Tradit. Herb. Drugs 2007, 38, 455-456.

47. Meeran, N.; Fizur, M.; Goyal, S.N.; Suchal, K.; Sharma, C.; Patil, C.R.; Ojha, S.K. Pharmacological properties, molecular mechanisms, and pharmaceutical development of asiatic acid: A pentacyclic triterpenoid of therapeutic promise. Front. Pharmacol. 2018, 9, 892. [CrossRef]

48. Chassaud, L.F.; Fry, B.J.; Hawkins, D.R.; Lewis, J.D.; Sword, I.P.; Taylor, T.; Hathway, D.E. The metabolism of asiatic acid,madecassic acid and asiaticoside in the rat. Arzneimittelforschung 1971, 21, 1379-1384.

49. Zheng, X.; Wang, S. Determination of asiatic acid in beagle dog plasma after oral administration of Centella asiatica extract by precolumn derivatization RP-HPLC. J. Chromatogr. B 2009, 877, 477-481. [CrossRef]

50. Yuan, Y.; Zhang, H.; Sun, F.; Sun, S.; Zhu, Z.; Chai, Y. Biopharmaceutical and pharmacokinetic characterization of asiatic acid in Centella asiatica as determined by a sensitive and robust HPLC-MS method. J. Ethnopharmacol. 2015, 163, 31-38. [CrossRef]

51. Lee, K.Y.; Bae, O.; Serfozo, K.; Hejabian, S.; Moussa, A.; Reeves, M.; Rumbeiha, W.; Fitzgerald, S.D.; Stein, G.; Baek, S. Asiatic acid attenuates infarct volume, mitochondrial dysfunction, and matrix metalloproteinase-9 induction after focal cerebral ischemia. Stroke 2012, 43, 1632-1638. [CrossRef]

52. Lee, K.Y.; Bae, O.; Weinstock, S.; Kassab, M.; Majid, A. Neuroprotective effect of asiatic acid in rat model of focal embolic stroke. Biol. Pharm. Bull. 2014, 37, 1397-1401. [CrossRef]

53. Chao, P.; Yin, M.; Mong, M. Anti-apoptotic and anti-glycative effects of asiatic acid in the brain of D-galactose treated mice. Food Funct. 2015, 6, 542-548. [CrossRef]

54. Chao, P.; Lee, H.; Yin, M. Asiatic acid attenuated apoptotic and inflammatory stress in the striatum of MPTP-treated mice. Food Funct. 2016, 7, 1999-2005. [CrossRef]

55. Grimaldi, R.; De Ponti, F.; D’angelo, L.; Caravaggi, M.; Guidi, G.; Lecchini, S.; Frigo, G.; Crema, A. Pharmacokinetics of the total triterpenic fraction of Centella asiatica after single and multiple administrations to healthy volunteers. A new assay for asiatic acid. J. Ethnopharmacol. 1990, 28, 235-241. [CrossRef]

56. Rush, W.; Murray, G.; Graham, D. The comparative steady-state bioavailability of the active ingredients of Madecassol. Eur. J. Drug Metab. Pharmacokinet. 1993, 18, 323-326. [CrossRef] [PubMed]

57. Nair, S.N.; Menon, S.; Shailajan, S. A liquid chromatography/electrospray ionization tandem mass spectrometric method for quantification of asiatic acid from plasma: Application to pharmacokinetic study in rats. Rapid Commun. Mass Spectrom. 2012, 26, 1899-1908. [CrossRef] [PubMed]

58. Wang, T.; Leng, D.; Gao, F.; Jiang, C.; Xia, Y.; Dai, Y. A LC-ESI-MS method for the simultaneous determination of madecassoside and its metabolite madecassic acid in rat plasma: Comparison pharmacokinetics in normal and collagen-induced arthritic rats. Chin. J. Nat. Med. 2014, 12, 943-951. [CrossRef]

59. Gohil, K.J.; Patel, J.A.; Gajjar, A.K. Pharmacological Review on Centella asiatica: A Potential Herbal Cure-all. Indian. J. Pharm. Sci. 2010, 72, 546-556. [CrossRef]

60. Eun, H.C.; Lee, A.Y. Contact dermatitis due to madecassol. Contact Dermat. 1985, 13, 310-313. [CrossRef] [PubMed] 
61. Izu, R.; Aguirre, A.; Gil, N.; Diaz-Perez, J. Allergic contact dermatitis from a cream containing Centella asiatica extract. Contact Dermat. 1992, 26, 192-213. [CrossRef]

62. Hausen, B. Centella asiatica (Indian pennywort), an effective therapeutic but a weak sensitizer. Contact Dermat. 1993, 29, 175-179. [CrossRef]

63. Danese, P.; Carnevali, C.; Bertazzoni, M.G. Allergic contact dermatitis due to Centella asiatica extract. Contact Dermat. 1994, 31, 201. [CrossRef]

64. Bilbao, I.; Aguirre, A.; Zabala, R.; Gonzalez, R.; Raton, J.; Diaz Perez, J. Allergic contact dermatitis from butoxyethyl nicotinic acid and Centella asiatica extract. Contact Dermat. 1995, 33, 435-436. [CrossRef]

65. Gonzalo Garijo, M.A.; Revenga Arranz, F.; Bobadilla Gonzalez, P. Allergic contact dermatitis due to Centella asiatica: A new case. Allergol. Immunopathol. 1996, 24, 132-134.

66. Chivapat, S.; Chavalittumrong, P.; Tantisira, M.H. Acute and sub-chronic toxicity studies of a standardized extract of Centella asiatica ECa 233. Thai J. Pharm. Sci. 2011, 35, 55-64.

67. Chivapat, S.; Chavalittumrong, P.; Attawish, A.; Boonruad, T.; Bansiddhi, J.; Phadungpat, S.; Punyamong, S.; Mingmuang, J. Toxicity study of Centella asiatica (L) urban. J. Thai Tradit. Altern. Med. 2004, 2, 3-17.

68. Oruganti, M.; Roy, B.K.; Singh, K.K.; Prasad, R.; Kumar, S. Safety Assemment of Centella asiatica in albino rats. Pharmacogn. J. 2010, 2, 5-13. [CrossRef]

69. Jorge, O.; Jorge, A. Hepatotoxicity associated with the ingestion of Centella asiatica. Rev. Española Enferm. Dig. 2005, 97, 115-124. [CrossRef]

70. Dutta, T.; Basu, U. Crude extract of Centella asiatica and products derived from its glycosides as oral antifertility agents. Indian J. Exp. Biol. 1968, 6, 181-182.

71. Kartnig, T. Clinical applications of Centella asiatica (L.). Urb. Herbs Spices Med. Plants: Recent Adv. Bot. Hortic. Pharmacol. 1988, 3, 145-173.

72. Laerum, O.D.; Iversen, O.H. Reticuloses and epidermal tumors in hairless mice after topical skin applications of cantharidin and asiaticoside. Cancer Res. 1972, 32, 1463-1469. [PubMed]

73. Pan, Y.; Abd-Rashid, B.A.; Ismail, Z.; Ismail, R.; Mak, J.W.; Pook, P.C.; Er, H.M.; Ong, C.E. In vitro modulatory effects on three major human cytochrome P450 enzymes by multiple active constituents and extracts of Centella asiatica. J. Ethnopharmacol. 2010, 130, 275-283. [CrossRef] [PubMed]

74. Hou, Q.; Li, M.; Lu, Y.; Liu, D.; Li, C. Burn wound healing properties of asiaticoside and madecassoside. Exp. Ther. Med. 2016, 12, 1269-1274. [CrossRef] [PubMed]

75. Xu, X.; Wang, Y.; Wei, Z.; Wei, W.; Zhao, P.; Tong, B.; Xia, Y.; Dai, Y. Madecassic acid, the contributor to the anti-colitis effect of madecassoside, enhances the shift of Th17 toward Treg cells via the PPARI ${ }^{3} /$ AMPK/ACC1 pathway. Cell Death Dis. 2017, 8 , e2723. [CrossRef] [PubMed]

76. Haftek, M.; Mac-Mary, S.; Le Bitoux, M.A.; Creidi, P.; Seite, S.; Rougier, A.; Humbert, P. Clinical, biometric and structural evaluation of the long-term effects of a topical treatment with ascorbic acid and madecassoside in photoaged human skin. Exp. Dermatol. 2008, 17, 946-952. [CrossRef]

77. Wang, H.; Liu, M.; Du, S. Optimization of madecassoside liposomes using response surface methodology and evaluation of its stability. Int. J. Pharm. 2014, 473, 280-285. [CrossRef] [PubMed]

78. Liu, M.; Dai, Y.; Li, Y.; Luo, Y.; Huang, F.; Gong, Z.; Meng, Q. Madecassoside isolated from Centella asiatica herbs facilitates burn wound healing in mice. Planta Med. 2008, 74, 809-815. [CrossRef]

79. Yuliati, L.; Mardliyati, E.; Bramono, K.; Freisleben, H.J. Asiaticoside induces cell proliferation and collagen synthesis in human dermal fibroblasts. Universa Med. 2015, 34, 96-103. [CrossRef]

80. Bian, D.; Liu, M.; Li, Y.; Xia, Y.; Gong, Z.; Dai, Y. Madecassoside, a triterpenoid saponin isolated from Centella asiatica herbs, protects endothelial cells against oxidative stress. J. Biochem. Mol. Toxicol. 2012, 26, 399-406. [CrossRef]

81. Lee, J.; Kim, H.; Lee, M.H.; You, K.E.; Kwon, B.; Seo, H.J.; Park, J. Asiaticoside enhances normal human skin cell migration, attachment and growth in vitro wound healing model. Phytomedicine 2012, 19, 1223-1227. [CrossRef] [PubMed]

82. Shukla, A.; Rasik, A.; Jain, G.; Shankar, R.; Kulshrestha, D.; Dhawan, B. In vitro and in vivo wound healing activity of asiaticoside isolated from Centella asiatica. J. Ethnopharmacol. 1999, 65, 1-11. [CrossRef]

83. Kimura, Y.; Sumiyoshi, M.; Samukawa, K.; Satake, N.; Sakanaka, M. Facilitating action of asiaticoside at low doses on burn wound repair and its mechanism. Eur. J. Pharmacol. 2008, 584, 415-423. [CrossRef]

84. Shukla, A.; Rasik, A.M.; Dhawan, B.N. Asiaticoside-induced elevation of antioxidant levels in healing wounds. Phytother. Res. Int. J. Devoted Pharmacol. Toxicol. Eval. Nat. Prod. Deriv. 1999, 13, 50-54. [CrossRef]

85. Verma, N.; Kumari, U.; Mittal, S.; Mittal, A.K. Effect of asiaticoside on the healing of skin wounds in the carp Cirrhinus mrigala: An immunohistochemical investigation. Tissue Cell 2017, 49, 734-745. [CrossRef]

86. Jung, E.; Lee, J.A.; Shin, S.; Roh, K.B.; Kim, J.H.; Park, D. Madecassoside inhibits melanin synthesis by blocking ultraviolet-induced inflammation. Molecules 2013, 18, 15724-15736. [CrossRef]

87. Ling, Y.; Gong, Q.; Xiong, X.; Sun, L.; Zhao, W.; Zhu, W.; Lu, Y. Protective effect of madecassoside on $\mathrm{H}\left({ }_{2}\right) \mathrm{O}(2)$-induced oxidative stress and autophagy activation in human melanocytes. Oncotarget 2017, 8, 51066-51075. [CrossRef]

88. Song, J.; Xu, H.; Lu, Q.; Xu, Z.; Bian, D.; Xia, Y.; Wei, Z.; Gong, Z.; Dai, Y. Madecassoside suppresses migration of fibroblasts from keloids: Involvement of p38 kinase and PI3K signaling pathways. Burns 2012, 38, 677-684. [CrossRef] 
89. OuYang, Q.; Pan, Y.; Luo, H.; Xuan, C.; Liu, J.; Liu, J. MAD ointment ameliorates Imiquimod-induced psoriasiform dermatitis by inhibiting the IL-23/IL-17 axis in mice. Int. Immunopharmacol. 2016, 39, 369-376. [CrossRef]

90. Lee, J.; Jung, E.; Lee, H.; Seo, Y.; Koh, J.; Park, D. Evaluation of the effects of a preparation containing asiaticoside on periocular wrinkles of human volunteers. Int. J. Cosmet. Sci. 2008, 30, 167-173. [CrossRef]

91. Kwon, K.J.; Bae, S.; Kim, K.; An, I.S.; Ahn, K.J.; An, S.; Cha, H.J. Asiaticoside, a component of Centella asiatica, inhibits melanogenesis in B16F10 mouse melanoma. Mol. Med. Rep. 2014, 10, 503-507. [CrossRef] [PubMed]

92. Wang, Z.H. Anti-glycative effects of asiatic acid in human keratinocyte cells. Biomedicine 2014, 4, 19. [CrossRef]

93. Lee, Y.S.; Jin, D.; Beak, S.; Lee, E.; Kim, J. Inhibition of ultraviolet-A-modulated signaling pathways by asiatic acid and ursolic acid in HaCaT human keratinocytes. Eur. J. Pharmacol. 2003, 476, 173-178.

94. Song, J.; Dai, Y.; Bian, D.; Zhang, H.; Xu, X.; Xia, Y.; Gong, Z. Madecassoside induces apoptosis of keloid fibroblasts via a mitochondrial-dependent pathway. Drug Dev. Res. 2011, 72, 315-322. [CrossRef]

95. Wu, X.; Bian, D.; Dou, Y.; Gong, Z.; Tan, Q.; Xia, Y.; Dai, Y. Asiaticoside hinders the invasive growth of keloid fibroblasts through inhibition of the GDF-9/MAPK/Smad pathway. J. Biochem. Mol. Toxicol. 2017, 31, e21922. [CrossRef]

96. Tang, B.; Zhu, B.; Liang, Y.; Bi, L.; Hu, Z.; Chen, B.; Zhang, K.; Zhu, J. Asiaticoside suppresses collagen expression and TGFbeta/Smad signaling through inducing Smad7 and inhibiting TGF-betaRI and TGF-betaRII in keloid fibroblasts. Arch. Dermatol. Res. 2011, 303, 563-572. [CrossRef]

97. Lee, J.; Jung, E.; Kim, Y.; Park, J.; Park, J.; Hong, S.; Kim, J.; Hyun, C.; Kim, Y.S.; Park, D. Asiaticoside induces human collagen I synthesis through TGF $\beta$ receptor I kinase (T $\beta R I$ kinase)-independent Smad signaling. Planta Med. 2006, 72, 324-328. [CrossRef]

98. Ju-lin, X.; Shao-hai, Q.; Tian-zeng, L.; Bin, H.; Jing-ming, T.; Ying-bin, X.; Xu-sheng, L.; Bin, S.; Hui-zhen, L.; Yong, H. Effect of asiaticoside on hypertrophic scar in the rabbit ear model. J. Cutan. Pathol. 2009, 36, 234-239. [CrossRef]

99. Qi, S.; Xie, J.; Pan, S.; Xu, Y.; Li, T.; Tang, J.; Liu, X.; Shu, B.; Liu, P. Effects of asiaticoside on the expression of Smad protein by normal skin fibroblasts and hypertrophic scar fibroblasts. Clin. Exp. Dermatol. Clin. Dermatol. 2008, 33, 171-175. [CrossRef] [PubMed]

100. Bian, D.; Zhang, J.; Wu, X.; Dou, Y.; Yang, Y.; Tan, Q.; Xia, Y.; Gong, Z.; Dai, Y. Asiatic acid isolated from Centella asiatica inhibits TGF-beta1-induced collagen expression in human keloid fibroblasts via PPAR-gamma activation. Int. J. Biol. Sci. 2013, 9, 1032-1042. [CrossRef]

101. Smolen, J.S.; Aletaha, D.; Koeller, M.; Weisman, M.H.; Emery, P. New therapies for treatment of rheumatoid arthritis. Lancet 2007, 370, 1861-1874. [CrossRef]

102. Myers, L.K.; Rosloniec, E.F.; Cremer, M.A.; Kang, A.H. Collagen-induced arthritis, an animal model of autoimmunity. Life Sci. 1997, 61, 1861-1878. [CrossRef]

103. Kannan, K.; Ortmann, R.A.; Kimpel, D. Animal models of rheumatoid arthritis and their relevance to human disease. Pathophysiology 2005, 12, 167-181. [CrossRef] [PubMed]

104. Liu, M.; Dai, Y.; Yao, X.; Li, Y.; Luo, Y.; Xia, Y.; Gong, Z. Anti-rheumatoid arthritic effect of madecassoside on type II collageninduced arthritis in mice. Int. Immunopharmacol. 2008, 8, 1561-1566. [CrossRef] [PubMed]

105. Li, H.; Gong, X.; Zhang, L.; Zhang, Z.; Luo, F.; Zhou, Q.; Chen, J.; Wan, J. Madecassoside attenuates inflammatory response on collagen-induced arthritis in DBA/1 mice. Phytomedicine 2009, 16, 538-546. [CrossRef]

106. Wang, T.; Wei, Z.; Dou, Y.; Yang, Y.; Leng, D.; Kong, L.; Dai, Y.; Xia, Y. Intestinal interleukin-10 mobilization as a contributor to the anti-arthritis effect of orally administered madecassoside: A unique action mode of saponin compounds with poor bioavailability. Biochem. Pharmacol. 2015, 94, 30-38. [CrossRef]

107. Rose, B.J.; Kooyman, D.L. A tale of two joints: The role of matrix metalloproteases in cartilage biology. Dis. Markers 2016, 2016, 4895050. [CrossRef]

108. Yoshihara, Y.; Nakamura, H.; Obata, K.; Yamada, H.; Hayakawa, T.; Fujikawa, K.; Okada, Y. Matrix metalloproteinases and tissue inhibitors of metalloproteinases in synovial fluids from patients with rheumatoid arthritis or osteoarthritis. Ann. Rheum. Dis. 2000, 59, 455-461. [CrossRef]

109. Liacini, A.; Sylvester, J.; Li, W.Q.; Zafarullah, M. Inhibition of interleukin-1-stimulated MAP kinases, activating protein-1 (AP-1) and nuclear factor kappa B (NF-kB) transcription factors down-regulates matrix metalloproteinase gene expression in articular chondrocytes. Matrix Biol. 2002, 21, 251-262. [CrossRef]

110. Yu, W.G.; Shen, Y.; Wu, J.Z.; Gao, Y.B.; Zhang, L.X. Madecassoside impedes invasion of rheumatoid fibroblast-like synoviocyte from adjuvant arthritis rats via inhibition of NF-kappaB-mediated matrix metalloproteinase-13 expression. Chin. J. Nat. Med. 2018, 16, 330-338.

111. Sasmita, A.O.; Ling, A.P.K.; Voon, K.G.L.; Koh, R.Y.; Wong, Y.P. Madecassoside activates antineuroinflammatory mechanisms by inhibiting lipopolysaccharideinduced microglial inflammation. Int. J. Mol. Med. 2018, 41, 3033-3040. [CrossRef]

112. Lin, X.; Zhang, S.; Huang, R.; Wei, L.; Tan, S.; Liang, C.; Lv, S.; Chen, Y.; Liang, S.; Tian, Y.; et al. Protective effect of madecassoside against cognitive impairment induced by D-galactose in mice. Pharmacol. Biochem. Behav. 2014, 124, 434-442. [CrossRef]

113. Nalinratana, N.; Meksuriyen, D.; Ongpipattanakul, B. Differences in Neuritogenic Activity and Signaling Activation of Madecassoside, Asiaticoside, and Their Aglycones in Neuro-2a cells. Planta Med. 2018, 84, 1165-1173. [CrossRef]

114. Brinkhaus, B.; Lindner, M.; Schuppan, D.; Hahn, E. Chemical, pharmacological and clinical profile of the East Asian medical plant Centella aslatica. Phytomedicine 2000, 7, 427-448. [CrossRef] 
115. Mamun, A.A.; Hashimoto, M.; Katakura, M.; Matsuzaki, K.; Hossain, S.; Arai, H.; Shido, O. Neuroprotective Effect of Madecassoside Evaluated Using Amyloid B1-42-Mediated in Vitro and in Vivo Alzheimer's Disease Models. Int. J. Indig. Med. Plants 2014, $47,1669-1682$.

116. Mamun, A.; Hashimoto, M.; Hossain, S.; Katakura, M.; Arai, H.; Shido, O. Confirmation of the Experimentally-Proven Therapeutic Utility of Madecassoside in an A $\beta_{1-42}$ Infusion Rat Model of Alzheimer's Disease by in Silico Analyses. Adv. Alzheimer's Dis. 2014, 4, 37-44. [CrossRef]

117. Zhang, Z.; Li, X.; Li, D.; Luo, M.; Li, Y.; Song, L.; Jiang, X. Asiaticoside ameliorates $\beta$-amyloid-induced learning and memory deficits in rats by inhibiting mitochondrial apoptosis and reducing inflammatory factors. Exp. Ther. Med. 2017, 13, 413-420. [CrossRef] [PubMed]

118. Song, D.; Jiang, X.; Liu, Y.; Sun, Y.; Cao, S.; Zhang, Z. Asiaticoside attenuates cell growth inhibition and apoptosis induced by A $\beta 1-42$ via inhibiting the TLR4/NF-kB signaling pathway in human brain microvascular endothelial cells. Front. Pharmacol. 2018, 9, 28. [CrossRef]

119. Lin, X.; Huang, R.; Zhang, S.; Wei, L.; Zhuo, L.; Wu, X.; Tang, A.; Huang, Q. Beneficial effects of asiaticoside on cognitive deficits in senescence-accelerated mice. Fitoterapia 2013, 87, 69-77. [CrossRef]

120. Zhang, Z.; Cai, P.; Zhou, J.; Liu, M.; Jiang, X. Effects of asiaticoside on human umbilical vein endothelial cell apoptosis induced by Abeta1-42. Int. J. Clin. Exp. Med. 2015, 8, 15828-15833.

121. Hossain, S.; Hashimoto, M.; Katakura, M.; Al Mamun, A.; Shido, O. Medicinal value of asiaticoside for Alzheimer's disease as assessed using single-molecule-detection fluorescence correlation spectroscopy, laser-scanning microscopy, transmission electron microscopy, and in silico docking. BMC Complement. Altern. Med. 2015, 15, 1-14. [CrossRef] [PubMed]

122. Rather, M.A.; Thenmozhi, A.J.; Manivasagam, T.; Nataraj, J.; Essa, M.M.; Chidambaram, S.B. Asiatic acid nullified aluminium toxicity in in vitro model of Alzheimer's disease. Front. Biosci. (Elite Ed.) 2018, 10, 287-299.

123. Rather, M.A.; Thenmozhi, A.J.; Manivasagam, T.; Bharathi, M.D.; Essa, M.M.; Guillemin, G.J. Neuroprotective role of Asiatic acid in aluminium chloride induced rat model of Alzheimer's disease. Front. Biosci. (Schol. Ed.) 2018, 10, $262-275$.

124. Rather, M.A.; Justin-Thenmozhi, A.; Manivasagam, T.; Saravanababu, C.; Guillemin, G.J.; Essa, M.M. Asiatic acid attenuated aluminum chloride-induced tau pathology, oxidative stress and apoptosis via AKT/GSK-3 $\beta$ signaling pathway in Wistar rats. Neurotox. Res. 2019, 35, 955-968. [CrossRef]

125. Cheng, W.; Chen, W.; Wang, P.; Chu, J. Asiatic acid protects differentiated PC12 cells from A $\beta 25-35$-induced apoptosis and tau hyperphosphorylation via regulating PI3K/Akt/GSK-3 $\beta$ signaling. Life Sci. 2018, 208, 96-101. [CrossRef] [PubMed]

126. Zhang, X.; Wu, J.; Dou, Y.; Xia, B.; Rong, W.; Rimbach, G.; Lou, Y. Asiatic acid protects primary neurons against C2-ceramideinduced apoptosis. Eur. J. Pharmacol. 2012, 679, 51-59. [CrossRef] [PubMed]

127. Ternchoocheep, K.; Surangkul, D.; Ysothonsreekul, S. The recovery and protective effects of asiatic acid on differentiated human neuroblastoma SH-SY5Y cells cytotoxic-induced by cholesterol. Asian Pac. J. Trop. Biomed. 2017, 7, 416-420. [CrossRef]

128. Patil, S.P.; Maki, S.; Khedkar, S.A.; Rigby, A.C.; Chan, C. Withanolide A and asiatic acid modulate multiple targets associated with amyloid- $\beta$ precursor protein processing and amyloid- $\beta$ protein clearance. J. Nat. Prod. 2010, 73, 1196-1202. [CrossRef]

129. Nasir, M.; Habsah, M.; Zamzuri, I.; Rammes, G.; Hasnan, J.; Abdullah, J. Effects of asiatic acid on passive and active avoidance task in male Spraque-Dawley rats. J. Ethnopharmacol. 2011, 134, 203-209. [CrossRef]

130. Sirichoat, A.; Chaijaroonkhanarak, W.; Prachaney, P.; Pannangrong, W.; Leksomboon, R.; Chaichun, A.; Wigmore, P.; Welbat, J.U. Effects of asiatic acid on spatial working memory and cell proliferation in the adult rat hippocampus. Nutrients 2015, 7, 8413-8423. [CrossRef]

131. Chaisawang, P.; Sirichoat, A.; Chaijaroonkhanarak, W.; Pannangrong, W.; Sripanidkulchai, B.; Wigmore, P.; Welbat, J.U. Asiatic acid protects against cognitive deficits and reductions in cell proliferation and survival in the rat hippocampus caused by 5-fluorouracil chemotherapy. PLoS ONE 2017, 12, e0180650. [CrossRef] [PubMed]

132. Umka Welbat, J.; Sirichoat, A.; Chaijaroonkhanarak, W.; Prachaney, P.; Pannangrong, W.; Pakdeechote, P.; Sripanidkulchai, B.; Wigmore, P. Asiatic acid prevents the deleterious effects of valproic acid on cognition and hippocampal cell proliferation and survival. Nutrients 2016, 8, 303. [CrossRef]

133. Xu, C.; Qu, R.; Zhang, J.; Li, L.; Ma, S. Neuroprotective effects of madecassoside in early stage of Parkinson's disease induced by MPTP in rats. Fitoterapia 2013, 90, 112-118. [CrossRef] [PubMed]

134. Sampath, U.; Janardhanam, V.A. Asiaticoside, a trisaccaride triterpene induces biochemical and molecular variations in brain of mice with parkinsonism. Transl. Neurodegener. 2013, 2, 23. [CrossRef] [PubMed]

135. Xu, C.; Wang, Q.; Sun, L.; Li, X.; Deng, J.; Li, L.; Zhang, J.; Xu, R.; Ma, S. Asiaticoside: Attenuation of neurotoxicity induced by MPTP in a rat model of Parkinsonism via maintaining redox balance and up-regulating the ratio of Bcl-2/Bax. Pharmacol. Biochem. Behav. 2012, 100, 413-418. [CrossRef] [PubMed]

136. Nataraj, J.; Manivasagam, T.; Thenmozhi, A.J.; Essa, M.M. Neurotrophic effect of asiatic acid, a triterpene of Centella asiatica against chronic 1-methyl 4-phenyl 1,2,3,6-tetrahydropyridine hydrochloride/probenecid mouse model of Parkinson's disease: The role of MAPK, PI3K-Akt-GSK3 $\beta$ and mTOR signalling pathways. Neurochem. Res. 2017, 42, 1354-1365. [CrossRef]

137. Xiong, Y.; Ding, H.; Xu, M.; Gao, J. Protective effects of asiatic acid on rotenone-or H 2 O 2-induced injury in SH-SY5Y cells. Neurochem. Res. 2009, 34, 746-754. [CrossRef]

138. Ding, H.; Xiong, Y.; Sun, J.; Chen, C.; Gao, J.; Xu, H. Asiatic acid prevents oxidative stress and apoptosis by inhibiting the translocation of $\alpha$-synuclein into mitochondria. Front. Neurosci. 2018, 12, 431. [CrossRef] 
139. Nataraj, J.; Manivasagam, T.; Justin Thenmozhi, A.; Essa, M.M. Neuroprotective effect of asiatic acid on rotenone-induced mitochondrial dysfunction and oxidative stress-mediated apoptosis in differentiated SH-SYS5Y cells. Nutr. Neurosci. 2017, 20, 351-359. [CrossRef]

140. Gopi, M.; Janardhanam, V.A. Asiaticoside: Attenuation of rotenone induced oxidative burden in a rat model of hemiparkinsonism by maintaining the phosphoinositide-mediated synaptic integrity. Pharmacol. Biochem. Behav. 2017, 155, 1-15. [CrossRef]

141. Luo, Y.; Yang, Y.P.; Liu, J.; Li, W.H.; Yang, J.; Sui, X.; Yuan, X.; Nie, Z.Y.; Liu, Y.Q.; Chen, D.; et al. Neuroprotective effects of madecassoside against focal cerebral ischemia reperfusion injury in rats. Brain Res. 2014, 1565, 37-47. [CrossRef]

142. Luo, Y.; Wang, C.; Li, W.H.; Liu, J.; He, H.H.; Long, J.H.; Yang, J.; Sui, X.; Wang, S.; You, Z.; et al. Madecassoside protects BV2 microglial cells from oxygen-glucose deprivation/reperfusion-induced injury via inhibition of the toll-like receptor 4 signaling pathway. Brain Res. 2018, 1679, 144-154. [CrossRef] [PubMed]

143. Sun, T.; Liu, B.; Li, P. Nerve Protective Effect of Asiaticoside against Ischemia-Hypoxia in Cultured Rat Cortex Neurons. Med. Sci. Monit. 2015, 21, 3036-3041. [CrossRef] [PubMed]

144. Chen, S.; Yin, Z.; Jiang, C.; Ma, Z.; Fu, Q.; Qu, R.; Ma, S. Asiaticoside attenuates memory impairment induced by transient cerebral ischemia-reperfusion in mice through anti-inflammatory mechanism. Pharmacol. Biochem. Behav. 2014, 122, 7-15. [CrossRef]

145. Krishnamurthy, R.G.; Senut, M.; Zemke, D.; Min, J.; Frenkel, M.B.; Greenberg, E.J.; Yu, S.; Ahn, N.; Goudreau, J.; Kassab, M. Asiatic acid, a pentacyclic triterpene from Centella asiatica, is neuroprotective in a mouse model of focal cerebral ischemia. $J$. Neurosci. Res. 2009, 87, 2541-2550. [CrossRef] [PubMed]

146. Park, J.; Seo, Y.H.; Jang, J.; Jeong, C.; Lee, S.; Park, B. Asiatic acid attenuates methamphetamine-induced neuroinflammation and neurotoxicity through blocking of NF-kB/STAT3/ERK and mitochondria-mediated apoptosis pathway. J. Neuroinflammation 2017, 14, 240. [CrossRef]

147. Loganathan, C.; Thayumanavan, P. Asiatic acid prevents the quinolinic acid-induced oxidative stress and cognitive impairment. Metab. Brain Dis. 2018, 33, 151-159. [CrossRef]

148. Liang, X.; Huang, Y.N.; Chen, S.W.; Wang, W.J.; Xu, N.; Cui, S.; Liu, X.H.; Zhang, H.; Liu, Y.N.; Liu, S. Antidepressant-like effect of asiaticoside in mice. Pharmacol. Biochem. Behav. 2008, 89, 444-449. [CrossRef]

149. Hou, T.; Li, X.; Peng, C. Borneol enhances the antidepressant effects of asiaticoside by promoting its distribution into the brain. Neurosci. Lett. 2017, 646, 56-61. [CrossRef]

150. Luo, L.; Liu, X.; Mu, R.; Wu, Y.; Liu, B.; Geng, D.; Liu, Q.; Yi, L. Hippocampal BDNF signaling restored with chronic asiaticoside treatment in depression-like mice. Brain Res. Bull. 2015, 114, 62-69. [CrossRef]

151. Ceremuga, T.E.; Valdivieso, D.; Kenner, C.; Lucia, A.; Lathrop, K.; Stailey, O.; Bailey, H.; Criss, J.; Linton, J.; Fried, J. Evaluation of the anxiolytic and antidepressant effects of asiatic acid, a compound from Gotu kola or Centella asiatica, in the male Sprague Dawley rat. AANA J. 2015, 83.

152. Chen, S.W.; Wang, W.J.; Li, W.J.; Wang, R.; Li, Y.L.; Huang, Y.N.; Liang, X. Anxiolytic-like effect of asiaticoside in mice. Pharmacol. Biochem. Behav. 2006, 85, 339-344. [CrossRef]

153. Wijeweera, P.; Arnason, J.; Koszycki, D.; Merali, Z. Evaluation of anxiolytic properties of Gotukola-(Centella asiatica) extracts and asiaticoside in rat behavioral models. Phytomedicine 2006, 13, 668-676. [CrossRef]

154. Bobade, V.; Bodhankar, S.L.; Aswar, U.; Vishwaraman, M.; Thakurdesai, P. Prophylactic effects of asiaticoside-based standardized extract of Centella asiatica (L.) Urban leaves on experimental migraine: Involvement of 5HT1A/1B receptors. Chin. J. Nat. Med. 2015, 13, 274-282. [CrossRef]

155. Qi, F.Y.; Yang, L.; Tian, Z.; Zhao, M.G.; Liu, S.B.; An, J.Z. Neuroprotective effects of Asiaticoside. Neural Regen. Res. 2014, 9 , 1275-1282. [CrossRef] [PubMed]

156. Xu, M.; Xiong, Y.; Liu, J.; Qian, J.; Zhu, L.; Gao, J. Asiatic acid, a pentacyclic triterpene in Centella asiatica, attenuates glutamateinduced cognitive deficits in mice and apoptosis in SH-SY5Y cells. Acta Pharmacol. Sin. 2012, 33, 578-587. [CrossRef] [PubMed]

157. Wang, Z.; Mong, M.; Yang, Y.; Yin, M. Asiatic acid and maslinic acid attenuated kainic acid-induced seizure through decreasing hippocampal inflammatory and oxidative stress. Epilepsy Res. 2018, 139, 28-34. [CrossRef] [PubMed]

158. Yin, Z.; Yu, H.; Chen, S.; Ma, C.; Ma, X.; Xu, L.; Ma, Z.; Qu, R.; Ma, S. Asiaticoside attenuates diabetes-induced cognition deficits by regulating PI3K/Akt/NF-kB pathway. Behav. Brain Res. 2015, 292, 288-299. [CrossRef]

159. Yellon, D.M.; Baxter, G.F. Reperfusion injury revisited: Is there a role for growth factor signaling in limiting lethal reperfusion injury? Trends Cardiovasc. Med. 1999, 9, 245-249. [CrossRef]

160. Yellon, D.M.; Baxter, G.F. Protecting the ischaemic and reperfused myocardium in acute myocardial infarction: Distant dream or near reality? Heart 2000, 83, 381-387. [CrossRef]

161. Li, G.G.; Bian, G.X.; Ren, J.P.; Wen, L.Q.; Zhang, M.; Lu, Q.J. Protective effect of madecassoside against reperfusion injury after regional ischemia in rabbit heart in vivo. Yao Xue Xue Bao 2007, 42, 475-480.

162. Bian, G.X.; Li, G.G.; Yang, Y.; Liu, R.T.; Ren, J.P.; Wen, L.Q.; Guo, S.M.; Lu, Q.J. Madecassoside reduces ischemia-reperfusion injury on regional ischemia induced heart infarction in rat. Biol. Pharm. Bull. 2008, 31, 458-463. [CrossRef]

163. Cao, W.; Li, X.; Zhang, X.; Hou, Y.; Zeng, A.; Xie, Y.; Wang, S. Madecassoside suppresses LPS-induced TNF- $\alpha$ production in cardiomyocytes through inhibition of ERK, p38, and NF-kB activity. Int. Immunopharmacol. 2010, 10, 723-729. [CrossRef]

164. Huang, X.; Zuo, L.; Lv, Y.; Chen, C.; Yang, Y.; Xin, H.; Li, Y.; Qian, Y. Asiatic acid attenuates myocardial ischemia/reperfusion injury via Akt/GSK-3 $\beta / \mathrm{HIF}-1 \alpha$ signaling in rat H9c2 cardiomyocytes. Molecules 2016, 21, 1248. [CrossRef] 
165. Chan, C.; Mong, M.; Liu, W.; Huang, C.; Yin, M. Three pentacyclic triterpenes protect H9c2 cardiomyoblast cells against high-glucose-induced injury. Free Radic. Res. 2014, 48, 402-411. [CrossRef] [PubMed]

166. Liu, J.; Chen, L.; Lu, H. Asiatic acid enhances antioxidant and anti-inflammatory activity to suppress isoproterenol induced cardiotoxicity. Int. J. Pharmacol. 2018, 14, 1038-1045. [CrossRef]

167. Gao, C.; Wang, F.; Wang, Z.; Zhang, J.; Yang, X. Asiatic acid inhibits lactate-induced cardiomyocyte apoptosis through the regulation of the lactate signaling cascade. Int. J. Mol. Med. 2016, 38, 1823-1830. [CrossRef] [PubMed]

168. Wu, K.; Hu, M.; Chen, Z.; Xiang, F.; Chen, G.; Yan, W.; Peng, Q.; Chen, X. Asiatic acid enhances survival of human AC16 cardiomyocytes under hypoxia by upregulating miR-1290. IUBMB Life 2017, 69, 660-667. [CrossRef] [PubMed]

169. Si, L.; Xu, J.; Yi, C.; Xu, X.; Ma, C.; Yang, J.; Wang, F.; Zhang, Y.; Wang, X. Asiatic acid attenuates the progression of left ventricular hypertrophy and heart failure induced by pressure overload by inhibiting myocardial remodeling in mice. J. Cardiovasc. Pharmacol. 2015, 66, 558-568. [CrossRef]

170. Huo, L.; Shi, W.; Chong, L.; Wang, J.; Zhang, K.; Li, Y. Asiatic acid inhibits left ventricular remodeling and improves cardiac function in a rat model of myocardial infarction. Exp. Ther. Med. 2016, 11, 57-64. [CrossRef] [PubMed]

171. Si, L.; Xu, J.; Yi, C.; Xu, X.; Wang, F.; Gu, W.; Zhang, Y.; Wang, X. Asiatic acid attenuates cardiac hypertrophy by blocking transforming growth factor- $\beta 1$-mediated hypertrophic signaling in vitro and in vivo. Int. J. Mol. Med. 2014, 34, 499-506. [CrossRef]

172. Ma, Z.; Dai, J.; Wei, W.; Zhang, W.; Xu, S.; Liao, H.; Yang, Z.; Tang, Q. Asiatic acid protects against cardiac hypertrophy through activating AMPK $\alpha$ signalling pathway. Int. J. Biol. Sci. 2016, 12, 861. [CrossRef] [PubMed]

173. Xu, X.; Si, L.; Xu, J.; Yi, C.; Wang, F.; Gu, W.; Zhang, Y.; Wang, X. Asiatic acid inhibits cardiac hypertrophy by blocking interleukin-1beta-activated nuclear factor-kappaB signaling in vitro and in vivo. J. Thorac. Dis. 2015, 7, 1787-1797. [CrossRef] [PubMed]

174. Bunbupha, S.; Pakdeechote, P.; Kukongviriyapan, U.; Prachaney, P.; Kukongviriyapan, V. Asiatic acid reduces blood pressure by enhancing nitric oxide bioavailability with modulation of eNOS and p47phox expression in L-NAME-induced hypertensive rats. Phytother. Res. 2014, 28, 1506-1512. [CrossRef] [PubMed]

175. Bunbupha, S.; Prachaney, P.; Kukongviriyapan, U.; Kukongviriyapan, V.; Welbat, J.U.; Pakdeechote, P. Asiatic acid alleviates cardiovascular remodelling in rats with L-NAME-induced hypertension. Clin. Exp. Pharmacol. Physiol. 2015, 42, 1189-1197. [CrossRef]

176. Pakdeechote, P.; Bunbupha, S.; Kukongviriyapan, U.; Prachaney, P.; Khrisanapant, W.; Kukongviriyapan, V. Asiatic acid alleviates hemodynamic and metabolic alterations via restoring eNOS/iNOS expression, oxidative stress, and inflammation in diet-induced metabolic syndrome rats. Nutrients 2014, 6, 355-370. [CrossRef]

177. Maneesai, P.; Bunbupha, S.; Kukongviriyapan, U.; Prachaney, P.; Tangsucharit, P.; Kukongviriyapan, V.; Pakdeechote, P. Asiatic acid attenuates renin-angiotensin system activation and improves vascular function in high-carbohydrate, high-fat diet fed rats. BMC Complement. Altern. Med. 2016, 16, 123. [CrossRef]

178. Hung, Y.; Yang, H.; Yin, M. Asiatic acid and maslinic acid protected heart via anti-glycative and anti-coagulatory activities in diabetic mice. Food Funct. 2015, 6, 2967-2974. [CrossRef]

179. Moran, A.E.; Roth, G.A.; Narula, J.; Mensah, G.A. 1990-2010 Global Cardiovascular Disease Atlas. Glob. Heart 2014, 9, 3-16. [CrossRef]

180. Fong, L.Y.; Ng, C.T.; Zakaria, Z.A.; Baharuldin, M.T.H.; Arifah, A.K.; Hakim, M.N.; Zuraini, A. Asiaticoside inhibits TNF- $\alpha-$ induced endothelial hyperpermeability of human aortic endothelial cells. Phytother. Res. 2015, 29, 1501-1508. [CrossRef]

181. Jing, L.; Haitao, W.; Qiong, W.; Fu, Z.; Nan, Z.; Xuezheng, Z. Anti inflammatory effect of asiaticoside on human umbilical vein endothelial cells induced by ox-LDL. Cytotechnology 2018, 70, 855-864. [CrossRef] [PubMed]

182. Fong, L.Y.; Ng, C.T.; Cheok, Z.L.; Moklas, M.A.M.; Hakim, M.N.; Ahmad, Z. Barrier protective effect of asiatic acid in TNF- $\alpha-$ induced activation of human aortic endothelial cells. Phytomedicine 2016, 23, 191-199. [CrossRef] [PubMed]

183. Fong, L.Y.; Ng, C.T.; Yong, Y.K.; Hakim, M.N.; Ahmad, Z. Asiatic acid stabilizes cytoskeletal proteins and prevents TNF- $\alpha$-induced disorganization of cell-cell junctions in human aortic endothelial cells. Vasc. Pharmacol. 2019, 117, 15-26. [CrossRef] [PubMed]

184. King, T.E., Jr.; Pardo, A.; Selman, M. Idiopathic pulmonary fibrosis. Lancet 2011, 378, 1949-1961. [CrossRef]

185. Zhang, L.N.; Zheng, J.J.; Zhang, L.; Gong, X.; Huang, H.; Wang, C.D.; Wang, B.; Wu, M.J.; Li, X.H.; Sun, W.J.; et al. Protective effects of asiaticoside on septic lung injury in mice. Exp. Toxicol. Pathol. 2011, 63, 519-525. [CrossRef]

186. Lu, G.X.; Bian, D.F.; Ji, Y.; Guo, J.M.; Wei, Z.F.; Jiang, S.D.; Xia, Y.F.; Dai, Y. Madecassoside ameliorates bleomycin-induced pulmonary fibrosis in mice by downregulating collagen deposition. Phytother. Res. 2014, 28, 1224-1231. [CrossRef]

187. Xia, Y.; Xia, Y.F.; Lv, Q.; Yue, M.F.; Qiao, S.M.; Yang, Y.; Wei, Z.F.; Dai, Y. Madecassoside ameliorates bleomycin-induced pulmonary fibrosis in mice through promoting the generation of hepatocyte growth factor via PPAR-gamma in colon. Br. J. Pharmacol. 2016, 173, 1219-1235. [CrossRef]

188. Ebina, M.; Shimizukawa, M.; Narumi, K.; Miki, M.; Koinuma, D.; Watanabe, M.; Munakata, H.; Nukiwa, T. Towards an effective gene therapy for idiopathic pulmonary fibrosis: Anti-inflammation, antifibrosis, and regeneration. Chest 2002, 121, 32S-33S. [CrossRef]

189. Dohi, M.; Hasegawa, T.; Yamamoto, K.; Marshall, B.C. Hepatocyte growth factor attenuates collagen accumulation in a murine model of pulmonary fibrosis. Am. J. Respir. Crit. Care Med. 2000, 162, 2302-2307. [CrossRef] 
190. Dong, S.; Liu, Y.; Wei, F.; Tan, H.; Han, Z. Asiatic acid ameliorates pulmonary fibrosis induced by bleomycin (BLM) via suppressing pro-fibrotic and inflammatory signaling pathways. Biomed. Pharmacother. 2017, 89, 1297-1309. [CrossRef]

191. Johnson, E.R.; Matthay, M.A. Acute lung injury: Epidemiology, pathogenesis, and treatment. J. Aerosol Med. Pulm. Drug Deliv. 2010, 23, 243-252. [CrossRef]

192. Zhang, Z.; Qin, D.; Wan, J.; Zhou, Q.; Xiao, S.; Wu, K. Effects of asiaticoside on the balance of inflammatory factors of mouse's acute lung injury induced by LPS. Zhong Yao Cai Zhongyaocai J. Chin. Med. Mater. 2008, 31, 547-549.

193. Qiu, J.; Yu, L.; Zhang, X.; Wu, Q.; Wang, D.; Wang, X.; Xia, C.; Feng, H. Asiaticoside attenuates lipopolysaccharide-induced acute lung injury via down-regulation of NF-kB signaling pathway. Int. Immunopharmacol. 2015, 26, 181-187. [CrossRef]

194. Li, Z.; Xiao, X.; Yang, M. Asiatic acid inhibits lipopolysaccharide-induced acute lung injury in mice. Inflammation 2016, 39, 1642-1648. [CrossRef] [PubMed]

195. Jiang, W.; Li, M.; He, F.; Yao, W.; Bian, Z.; Wang, X.; Zhu, L. Protective effects of asiatic acid against spinal cord injury-induced acute lung injury in rats. Inflammation 2016, 39, 1853-1861. [CrossRef]

196. Lee, J.; Park, H.A.; Kwon, O.; Jang, Y.; Kim, J.Y.; Choi, B.K.; Lee, H.J.; Lee, S.; Paik, J.; Oh, S. Asiatic acid inhibits pulmonary inflammation induced by cigarette smoke. Int. Immunopharmacol. 2016, 39, 208-217. [CrossRef] [PubMed]

197. Elsherbiny, N.M.; El-Sherbiny, M. Thymoquinone attenuates Doxorubicin-induced nephrotoxicity in rats: Role of Nrf2 and NOX4. Chem. Biol. Interact. 2014, 223, 102-108. [CrossRef]

198. Chandran, K.; Aggarwal, D.; Migrino, R.Q.; Joseph, J.; McAllister, D.; Konorev, E.A.; Antholine, W.E.; Zielonka, J.; Srinivasan, S.; Avadhani, N.G. Doxorubicin inactivates myocardial cytochrome c oxidase in rats: Cardioprotection by Mito-Q. Biophys. J. 2009, 96, 1388-1398. [CrossRef] [PubMed]

199. Singla, S.; Kumar, N.R.; Kaur, J. In vivo Studies on the Protective Effect of Propolis on Doxorubicin-Induced Toxicity in Liver of Male Rats. Toxicol. Int. 2014, 21, 191-195. [CrossRef] [PubMed]

200. Simmons, T.W.; JAMALL, I.S. Relative importance of intracellular glutathione peroxidase and catalase in vivo for prevention of peroxidation to the heart. Cardiovasc. Res. 1989, 23, 774-779. [CrossRef] [PubMed]

201. Su, Z.; Ye, J.; Qin, Z.; Ding, X. Protective effects of madecassoside against Doxorubicin induced nephrotoxicity in vivo and in vitro. Sci. Rep. 2015, 5, 18314. [CrossRef]

202. Xu, C.; Wang, W.; Xu, M.; Zhang, J. Asiatic acid ameliorates tubulointerstitial fibrosis in mice with ureteral obstruction. Exp. Ther. Med. 2013, 6, 731-736. [CrossRef]

203. Meng, X.M.; Zhang, Y.; Huang, X.R.; Ren, G.L.; Li, J.; Lan, H.Y. Treatment of renal fibrosis by rebalancing TGF-beta/Smad signaling with the combination of asiatic acid and naringenin. Oncotarget 2015, 6, 36984-36997. [CrossRef] [PubMed]

204. Yang, C.; Guo, Y.; Huang, T.; Zhao, J.; Huang, X.; Tang, H.; An, N.; Pan, Q.; Xu, Y.; Liu, H. Asiatic acid protects against cisplatin-induced acute kidney injury via anti-apoptosis and anti-inflammation. Biomed. Pharmacother. 2018, 107, $1354-1362$. [CrossRef] [PubMed]

205. Kimbell, B.; Murray, S.A. What is the patient experience in advanced liver disease? A scoping review of the literature. BMJ Support. Palliat. Care 2015, 5, 471-480. [CrossRef] [PubMed]

206. Hishinuma, I.; Nagakawa, J.; Hirota, K.; Miyamoto, K.; Tsukidate, K.; Yamanaka, T.; Katayama, K.; Yamatsu, I. Involvement of tumor necrosis factor- $\alpha$ in development of hepatic injury in galactosamine-sensitized mice. Hepatology 1990, 12, $1187-1191$. [CrossRef]

207. Wang, W.; Wu, L.; Li, Q.; Zhang, Z.; Xu, L.; Lin, C.; Gao, L.; Zhao, K.; Liang, F.; Zhang, Q.; et al. Madecassoside prevents acute liver failure in LPS/D-GalN-induced mice by inhibiting p38/NF-kappaB and activating Nrf2/HO-1 signaling. Biomed. Pharmacother. 2018, 103, 1137-1145. [CrossRef]

208. Zhang, L.; Li, H.; Gong, X.; Luo, F.; Wang, B.; Hu, N.; Wang, C.; Zhang, Z.; Wan, J. Protective effects of Asiaticoside on acute liver injury induced by lipopolysaccharide/D-galactosamine in mice. Phytomedicine 2010, 17, 811-819. [CrossRef] [PubMed]

209. Ma, K.; Zhang, Y.; Zhu, D.; Lou, Y. Protective effects of asiatic acid against D-galactosamine/lipopolysaccharide-induced hepatotoxicity in hepatocytes and kupffer cells co-cultured system via redox-regulated leukotriene C4 synthase expression pathway. Eur. J. Pharmacol. 2009, 603, 98-107. [CrossRef]

210. Lee, Y.A.; Wallace, M.C.; Friedman, S.L. Pathobiology of liver fibrosis: A translational success story. Gut 2015, 64, 830-841. [CrossRef]

211. Tang, L.X.; He, R.H.; Yang, G.; Tan, J.J.; Zhou, L.; Meng, X.M.; Huang, X.R.; Lan, H.Y. Asiatic acid inhibits liver fibrosis by blocking TGF-beta/Smad signaling in vivo and in vitro. PLoS ONE 2012, 7, e31350. [CrossRef]

212. Wei, L.; Chen, Q.; Guo, A.; Fan, J.; Wang, R.; Zhang, H. Asiatic acid attenuates CCl4-induced liver fibrosis in rats by regulating the PI3K/AKT/mTOR and Bcl-2/Bax signaling pathways. Int. Immunopharmacol. 2018, 60, 1-8. [CrossRef]

213. Fan, J.; Chen, Q.; Wei, L.; Zhou, X.; Wang, R.; Zhang, H. Asiatic acid ameliorates CCl4-induced liver fibrosis in rats: Involvement of Nrf2/ARE, NF-kappaB/IkappaBalpha, and JAK1/STAT3 signaling pathways. Drug Des. Dev. Ther. 2018, 12, $3595-3605$. [CrossRef]

214. Wei, J.; Huang, Q.; Huang, R.; Chen, Y.; Lv, S.; Wei, L.; Liang, C.; Liang, S.; Zhuo, L.; Lin, X. Asiatic acid from Potentilla chinensis attenuate ethanol-induced hepatic injury via suppression of oxidative stress and Kupffer cell activation. Biol. Pharm. Bull. 2013, 36, 1980-1989. [CrossRef]

215. Yan, S.; Yang, H.; Lee, Y.; Lin, C.; Chang, M.; Yin, M. Asiatic acid ameliorates hepatic lipid accumulation and insulin resistance in mice consuming a high-fat diet. J. Agric. Food Chem. 2014, 62, 4625-4631. [CrossRef] 
216. Lu, Y.; Kan, H.; Wang, Y.; Wang, D.; Wang, X.; Gao, J.; Zhu, L. Asiatic acid ameliorates hepatic ischemia/reperfusion injury in rats via mitochondria-targeted protective mechanism. Toxicol. Appl. Pharmacol. 2018, 338, 214-223. [CrossRef]

217. Lu, Y.; Liu, S.; Wang, Y.; Wang, D.; Gao, J.; Zhu, L. Asiatic acid uncouples respiration in isolated mouse liver mitochondria and induces HepG2 cells death. Eur. J. Pharmacol. 2016, 786, 212-223. [CrossRef] [PubMed]

218. Xu, Y.; Yao, J.; Zou, C.; Zhang, H.; Zhang, S.; Liu, J.; Ma, G.; Jiang, P.; Zhang, W. Asiatic acid protects against hepatic ischemia/reperfusion injury by inactivation of Kupffer cells via PPARgamma/NLRP3 inflammasome signaling pathway. Oncotarget 2017, 8, 86339-86355. [CrossRef]

219. Kamble, S.M.; Patil, C.R. Asiatic acid ameliorates doxorubicin-induced cardiac and hepato-renal toxicities with Nrf2 transcriptional factor activation in rats. Cardiovasc. Toxicol. 2018, 18, 131-141. [CrossRef] [PubMed]

220. Al-Saeedi, F.J. Study of the cytotoxicity of asiaticoside on rats and tumour cells. BMC Cancer 2014, 14, 220. [CrossRef] [PubMed]

221. Park, M.; Park, H.; Kim, W.; Cho, H.; Lee, J. Presence of autocrine hepatocyte growth factor-Met signaling and its role in proliferation and migration of SNU-484 gastric cancer cell line. Exp. Mol. Med. 2005, 37, 213-219. [CrossRef] [PubMed]

222. Ogunwobi, O.O.; Liu, C. Hepatocyte growth factor upregulation promotes carcinogenesis and epithelial-mesenchymal transition in hepatocellular carcinoma via Akt and COX-2 pathways. Clin. Exp. Metastasis 2011, 28, 721-731. [CrossRef]

223. Li, Z.; You, K.; Li, J.; Wang, Y.; Xu, H.; Gao, B.; Wang, J. Madecassoside suppresses proliferation and invasiveness of HGF-induced human hepatocellular carcinoma cells via PKC-cMET-ERK1/2-COX-2-PGE2 pathway. Int. Immunopharmacol. 2016, $33,24-32$. [CrossRef]

224. Zhang, H.; Zhang, M.; Tao, Y.; Wang, G.; Xia, B. Madecassic acid inhibits the mouse colon cancer growth by inducing apoptosis and immunomodulation. J. BUON 2014, 19, 372-376.

225. Al-Saeedi, F.J.; Bitar, M.; Pariyani, S. Effect of asiaticoside on 99mTc-tetrofosmin and 99mTc-sestamibi uptake in MCF-7 cells. J. Nucl. Med. Technol. 2011, 39, 279-283. [CrossRef]

226. Yingchun, L.; Huihan, W.; Rong, Z.; Guojun, Z.; Ying, Y.; Zhuogang, L. Antitumor Activity of Asiaticoside Against Multiple Myeloma Drug-Resistant Cancer Cells Is Mediated by Autophagy Induction, Activation of Effector Caspases, and Inhibition of Cell Migration, Invasion, and STAT-3 Signaling Pathway. Med. Sci. Monit. 2019, 25, 1355-1361. [CrossRef]

227. Chen, J.; Xu, Q.; Xu, H.; Huang, Z. Asiatic acid promotes p21 (WAF1/CIP1) protein stability through attenuation of NDR1/2 dependent phosphorylation of p21 (WAF1/CIP1) in HepG2 human hepatoma cells. Asian Pac. J. Cancer Prev. 2014, 15, 963-967. [CrossRef]

228. Lee, Y.S.; Jin, D.; Kwon, E.J.; Park, S.H.; Lee, E.; Jeong, T.C.; Nam, D.H.; Huh, K.; Kim, J. Asiatic acid, a triterpene, induces apoptosis through intracellular Ca2 release and enhanced expression of p53 in HepG2 human hepatoma cells. Cancer Lett. 2002, 186, 83-91. [CrossRef]

229. Li, J.; Huang, R.; Yao, G.; Ye, M.; Wang, H.; Pan, Y.; Xiao, J. Synthesis and biological evaluation of novel aniline-derived asiatic acid derivatives as potential anticancer agents. Eur. J. Med. Chem. 2014, 86, 175-188. [CrossRef]

230. Park, B.C.; Bosire, K.O.; Lee, E.; Lee, Y.S.; Kim, J. Asiatic acid induces apoptosis in SK-MEL-2 human melanoma cells. Cancer Lett. 2005, 218, 81-90. [CrossRef]

231. Park, B.C.; Paek, S.; Lee, Y.; Kim, S.; Lee, E.; Choi, H.G.; Yong, C.S.; Kim, J. Inhibitory effects of asiatic acid on 7, 12-dimethylbenz [a] anthracene and 12-O-tetradecanoylphorbol 13-acetate-induced tumor promotion in mice. Biol. Pharm. Bull. 2007, 30, 176-179. [CrossRef]

232. Kavitha, C.V.; Jain, A.K.; Agarwal, C.; Pierce, A.; Keating, A.; Huber, K.M.; Serkova, N.J.; Wempe, M.F.; Agarwal, R.; Deep, G. Asiatic acid induces endoplasmic reticulum stress and apoptotic death in glioblastoma multiforme cells both in vitro and in vivo. Mol. Carcinog. 2015, 54, 1417-1429. [CrossRef]

233. Cho, C.; Choi, D.; Cardone, M.; Kim, C.W.; Sinskey, A.; Rha, C. Glioblastoma cell death induced by asiatic acid. Cell Biol. Toxicol. 2006, 22, 393-408. [CrossRef]

234. Thakor, F.K.; Wan, K.; Welsby, P.J.; Welsby, G. Pharmacological effects of asiatic acid in glioblastoma cells under hypoxia. Mol. Cell. Biochem. 2017, 430, 179-190. [CrossRef] [PubMed]

235. Zhang, J.; Ai, L.; Lv, T.; Jiang, X.; Liu, F. Asiatic acid, a triterpene, inhibits cell proliferation through regulating the expression of focal adhesion kinase in multiple myeloma cells. Oncol. Lett. 2013, 6, 1762-1766. [CrossRef] [PubMed]

236. Siddique, A.I.; Mani, V.; Renganathan, S.; Ayyanar, R.; Nagappan, A.; Namasivayam, N. Asiatic acid abridges pre-neoplastic lesions, inflammation, cell proliferation and induces apoptosis in a rat model of colon carcinogenesis. Chem. Biol. Interact. 2017, 278, 197-211. [CrossRef] [PubMed]

237. Siddique, A.I.; Mani, V.; Arivalagan, S.; Thomas, N.S.; Namasivayam, N. Asiatic acid attenuates pre-neoplastic lesions, oxidative stress, biotransforming enzymes and histopathological alterations in 1,2-dimethylhydrazine-induced experimental rat colon carcinogenesis. Toxicol. Mech. Methods 2017, 27, 136-150. [CrossRef]

238. Tang, X.; Yang, X.; Jung, H.; Kim, S.; Jung, S.; Choi, D.; Park, W.; Park, H. Asiatic Acid Induces Colon Cancer Cell Growth Inhibition and Apoptosis through Mitochondrial Death Cascade. Biol. Pharm. Bull. 2009, 32, 1399-1405. [CrossRef] [PubMed]

239. Hao, Y.; Huang, J.; Ma, Y.; Chen, W.; Fan, Q.; Sun, X.; Shao, M.; Cai, H. Asiatic acid inhibits proliferation, migration and induces apoptosis by regulating Pdcd4 via the PI3K/Akt/mTOR/p70S6K signaling pathway in human colon carcinoma cells. Oncol. Lett. 2018, 15, 8223-8230. [CrossRef]

240. Bunpo, P.; Kataoka, K.; Arimochi, H.; Nakayama, H.; Kuwahara, T.; Vinitketkumnuen, U.; Ohnishi, Y. Inhibitory effects of asiatic acid and CPT-11 on growth of HT-29 cells. J. Med. Investig. 2005, 52, 65-73. [CrossRef] [PubMed] 
241. Ren, L.; Cao, Q.; Zhai, F.; Yang, S.; Zhang, H. Asiatic acid exerts anticancer potential in human ovarian cancer cells via suppression of PI3K/Akt/mTOR signalling. Pharm. Biol. 2016, 54, 2377-2382. [CrossRef] [PubMed]

242. Hsu, Y.; Kuo, P.; Lin, L.; Lin, C. Asiatic Acid, a Triterpene, Induces Apoptosis and Cell Cycle Arrest through Activation of Extracellular Signal-Regulated Kinase and p38 Mitogen-Activated Protein Kinase Pathways in Human Breast Cancer Cells. J. Pharmacol. Exp. Ther. 2005, 313, 333. [CrossRef] [PubMed]

243. Wu, T.; Geng, J.; Guo, W.; Gao, J.; Zhu, X. Asiatic acid inhibits lung cancer cell growth in vitro and in vivo by destroying mitochondria. Acta Pharm. Sin. B 2017, 7, 65-72. [CrossRef]

244. Kim, K.B.; Kim, K.; Bae, S.; Choi, Y.; Cha, H.J.; Kim, S.Y.; Lee, J.H.; Jeon, S.H.; Jung, H.J.; Ahn, K.J.; et al. MicroRNA-1290 promotes asiatic acidinduced apoptosis by decreasing BCL2 protein level in A549 nonsmall cell lung carcinoma cells. Oncol. Rep. 2014, 32, 1029-1036. [CrossRef]

245. Gurfinkel, D.M.; Chow, S.; Hurren, R.; Gronda, M.; Henderson, C.; Berube, C.; Hedley, D.W.; Schimmer, A.D. Disruption of the endoplasmic reticulum and increases in cytoplasmic calcium are early events in cell death induced by the natural triterpenoid Asiatic acid. Apoptosis 2006, 11, 1463-1471. [CrossRef]

246. Wu, Q.; Lv, T.; Chen, Y.; Wen, L.; Zhang, J.; Jiang, X.; Liu, F. Apoptosis of HL-60 human leukemia cells induced by Asiatic acid through modulation of B-cell lymphoma 2 family proteins and the mitogen-activated protein kinase signaling pathway. Mol. Med. Rep. 2015, 12, 1429-1434. [CrossRef]

247. Fitrianda, E.; Sukandar, E.Y.; Elfahmi, E.; Adnyana, I. Antidiabetic activity of extract, fractions, and asiaticoside compound isolated from Centella asiatica Linn. Leaves in alloxan-induced diabetic mice. Asian J. Pharm. Clin. Res. 2017, 10, $268-272$. [CrossRef]

248. Rahman, M.M.; Sayeed, M.S.B.; Haque, M.A.; Hassan, M.M.; Islam, S.A. Phytochemical screening, Antioxidant, Anti-Alzheimer and Anti-diabetic activities of Centella asiatica. J. Nat. Prod. Plant. Resour. 2012, 2, 504-511.

249. Radhika, S.; Senthilkumar, R.; Arumugam, P. A review on ethnic florae with antihyperglycemic efficacy. Int. J. Herb. Med. 2013, $1,55-62$.

250. Ramachandran, V.; Saravanan, R. Efficacy of asiatic acid, a pentacyclic triterpene on attenuating the key enzymes activities of carbohydrate metabolism in streptozotocin-induced diabetic rats. Phytomedicine 2013, 20, 230-236. [CrossRef]

251. Ramachandran, V.; Saravanan, R.; Senthilraja, P. Antidiabetic and antihyperlipidemic activity of asiatic acid in diabetic rats, role of HMG CoA: In vivo and in silico approaches. Phytomedicine 2014, 21, 225-232. [CrossRef] [PubMed]

252. Ramachandran, V.; Saravanan, R. Asiatic acid prevents lipid peroxidation and improves antioxidant status in rats with streptozotocin-induced diabetes. J. Funct. Foods 2013, 5, 1077-1087. [CrossRef]

253. Ramachandran, V.; Saravanan, R. Glucose uptake through translocation and activation of GLUT4 in PI3K/Akt signaling pathway by asiatic acid in diabetic rats. Hum. Exp. Toxicol. 2015, 34, 884-893. [CrossRef] [PubMed]

254. Sun, W.; Xu, G.; Guo, X.; Luo, G.; Wu, L.; Hou, Y.; Guo, X.; Zhou, J.; Xu, T.; Qin, L. Protective effects of asiatic acid in a spontaneous type 2 diabetic mouse model. Mol. Med. Rep. 2017, 16, 1333-1339. [CrossRef] [PubMed]

255. Liu, J.; He, T.; Lu, Q.; Shang, J.; Sun, H.; Zhang, L. Asiatic acid preserves beta cell mass and mitigates hyperglycemia in streptozocin-induced diabetic rats. Diabetes Metab. Res. 2010, 26, 448-454. [CrossRef]

256. Xue, W.; Qian, L.; Dong-Sheng, Y.; Yu-Peng, C.; Shang, J.; Zhang, L.; Hong-Bin, S.; Jun, L. Asiatic acid mitigates hyperglycemia and reduces islet fibrosis in Goto-Kakizaki rat, a spontaneous type 2 diabetic animal model. Chin. J. Nat. Med. 2015, 13, 529-534.

257. Hsu, Y.; Hung, Y.; Hu, L.; Lee, Y.; Yin, M. Anti-diabetic effects of madecassic acid and rotundic acid. Nutrients 2015, 7, 10065-10075. [CrossRef]

258. Arancibia-Radich, J.; González-Blázquez, R.; Alcala, M.; Martín-Ramos, M.; Viana, M.; Arribas, S.; Delporte, C.; FernándezAlfonso, M.S.; Somoza, B.; Gil-Ortega, M. Beneficial effects of murtilla extract and madecassic acid on insulin sensitivity and endothelial function in a model of diet-induced obesity. Sci. Rep. 2019, 9, 1-12. [CrossRef]

259. Swee Ching, T.; Ramkumar, R.; Subrat Kumar, B.; Purushothaman, K.; Fabian, D.; Ebenezer, C.; Stephen, A.; Furman, B.L.; Mayuren, C. Madecassoside protects pancreatic B cells from glucotoxicity and oxidative stress. In British Journal of Pharmacology; British Pharmacological Society: London, UK, 2019; Volume 176, p. 2990.

260. Chen, Y.N.; Wu, C.G.; Shi, B.M.; Qian, K.; Ding, Y. The protective effect of asiatic acid on podocytes in the kidney of diabetic rats. Am. J. Transl. Res. 2018, 10, 3733-3741.

261. Xing, Y.; Ji, Q.; Li, X.; Ming, J.; Zhang, N.; Zha, D.; Lin, Y. Asiaticoside protects cochlear hair cells from high glucose-induced oxidative stress via suppressing AGEs/RAGE/NF-кB pathway. Biomed. Pharmacother. 2017, 86, 531-536. [CrossRef] 